\title{
Sea Surface and High-Latitude Temperature Sensitivity to Radiative Forcing of Climate over Several Glacial Cycles
}

\author{
E. J. Rohling, M. MedinA-Elizalde, And J. G. SHEPHERD \\ School of Ocean and Earth Science, and National Oceanography Centre, Southampton, University of Southampton, \\ Southampton, United Kingdom \\ M. SIDDALL \\ Department of Earth Sciences, University of Bristol, Bristol, United Kingdom

\section{J. D. STANFORD} \\ School of Ocean and Earth Science, and National Oceanography Centre, Southampton, University of Southampton, \\ Southampton, United Kingdom
}

(Manuscript received 17 September 2010, in final form 26 July 2011)

\begin{abstract}
A compilation is presented of global sea surface temperature (SST) records that span around one glacial cycle or more, and it is compared with changes in the earth's radiative balance over the last 520000 years, as determined from greenhouse gas concentrations, albedo changes related to ice sheet area and atmospheric dust fluctuations, and insolation changes. A first scenario uses global mean values for the radiative changes, and a second scenario uses zonal means for $10^{\circ}$ latitude bands for a more regionally specific perspective. On the orbital time scales studied here, a smooth increase of SST response from the equator to high latitudes is found when comparison is made to global mean radiative forcing, but a sharply "stepped" increase at $20^{\circ}-30^{\circ}$ latitude when comparing with the more regionally specific forcings. The mean global SST sensitivities to radiative change are within similar limits for both scenarios, around $0.8 \pm 0.4^{\circ} \mathrm{C}\left(\mathrm{W} \mathrm{m}^{-2}\right)^{-1}$. Combined with previous estimates of 1.3-1.5 times stronger temperature sensitivity over land, this yields an estimate for global climate sensitivity of $0.85(-0.4 /+0.5)^{\circ} \mathrm{C}\left(\mathrm{W} \mathrm{m}^{-2}\right)^{-1}$, close to previous estimates. If aerosol (dust) feedback were to be considered as a fast feedback, then the estimated central value for SST sensitivity would change to $\sim 0.95^{\circ} \mathrm{C}\left(\mathrm{W} \mathrm{m}^{-2}\right)^{-1}$ and that for global climate sensitivity to $\sim 1.05^{\circ} \mathrm{C}\left(\mathrm{W} \mathrm{m}^{-2}\right)^{-1}$. The zonal-mean scenario allows an assessment of (long-term) "normalized amplification" for Greenland and Antarctic temperature sensitivities, which is the ratio of temperature sensitivity for those sites relative to the global mean sensitivity, normalized per watt per meter squared of radiative change. This ratio is found to be $0.9(-0.2 /+0.6)$ and $1.4(-0.4 /+1.1)$ for Greenland and Antarctica, respectively. Given its value close to 1 for Greenland, but that larger Arctic amplification on shorter time scales due to fast sea ice albedo processes cannot be excluded, it is suggested that current high Arctic sensitivity is mainly due to sea ice albedo feedback processes and may decrease considerably if and when the Arctic sea ice cover has been eliminated. The normalized amplification value of 1.4 for Antarctica supports previous reconstructions of polar amplification in that region. The authors propose that this amplified response resulted from approximately threefold glacial-interglacial changes in the area of sea ice cover around Antarctica.
\end{abstract}

\section{Introduction}

Records of palaeoclimate change through glacial cycles in the recent geological past provide important observational evidence concerning the climate response

Corresponding author address: E. J. Rohling, School of Ocean and Earth Science, University of Southampton, Southampton SO14 3ZH, United Kingdom.

E-mail: e.rohling@noc.soton.ac.uk to changes in radiative forcing (e.g., Hansen et al. 2007, 2008; Köhler et al. 2010; Masson-Delmotte et al. 2010a). However, uncertainties remain regarding important variables, such as temperature responses, the amplitude and causes of polar amplification, and about the magnitude of radiative forcing changes on those time scales.

With respect to the temperature responses, a key comparison is between the preindustrial present and the Last Glacial Maximum (LGM), the only past interval for which substantial spatial information has been collated 
(e.g., MARGO project members 2009). However, comparison of extreme states cannot portray the nature of the temperature responses to intermediate and temporal variations in climate forcing. For such an analysis, changes in the radiative budgets through time need to be compared with temperature time series. So far, such efforts have concentrated almost exclusively on temperature reconstructions from Antarctic ice cores, translated into global temperature changes using a single, fixed value for the Antarctic polar amplification factor (Hansen et al. 2007, 2008; Köhler et al. 2010); usually taken to be about 2, from a range of 1.2-2.1 based on Paleoclimate Modeling Intercomparison Project (PMIP) LGM simulations without dust forcing (Masson-Delmotte et al. 2006). Both Köhler et al. (2010) and Masson-Delmotte et al. (2010a) evaluate the polar amplification choice in a wider context (e.g., deep sea temperature), highlighting the need for a global synthesis of temperature records from other latitudes. In the absence of such a synthesis, important questions remain unanswered, such as (i) whether the Antarctic ice-core temperature record does indeed offer a reasonable approximation for the global temperature response and (ii) whether polar amplification is sufficiently represented by a simple constant and whether its potential range is sufficiently understood. In addition, no studies have yet considered the potential impact of spatial inhomogeneity in the forcing terms and their relative contributions to total radiative forcing changes.

This paper aims to address these issues through a more spatially explicit and global analysis of past temperature variability in comparison with regional and global mean radiative forcing. Temperature changes in the geological past for any location can be estimated from "proxy" data, which are calibrated to temperature using process models or empirical relationships. However, there are uncertainties and systematic biases involved in such procedures. In addition, different climatic settings (e.g., circulation regimes) may impose considerable spatial variability in the temperature responses to climate forcing, which needs to be adequately sampled. It is therefore important to take stock of existing time series of temperature reconstruction on a worldwide basis and to identify where improvements may be needed, such as increased data coverage/density. Here we present the first assessment of this type, as a foundation to be enriched by targeted future research.

With respect to the radiative forcing of climate, there is a steady increase in understanding of some of the major terms (notably greenhouse gas concentrations and icesheet area albedo), but only first-order information exists about others (e.g., atmospheric dust albedo). The globally averaged insolation fluctuations are considered to have contributed little in terms of total global radiative forcing changes (Hansen et al. 2007, 2008; Köhler et al. 2010), but insolation becomes an important term when considering radiative forcing of climate in a more regional sense. Finally, there are several terms for which no highly resolved, long time series exist (e.g., cloud cover, vegetation albedo, and sea ice albedo terms). These might be crudely approximated from modeling of past climates, but this is slightly circular in that aspects of model output are then used to approximate data.

Here we extend on the pioneering studies of Hansen et al. $(2007,2008)$ and Köhler et al. (2010) to reconstruct a time series of change in radiative climate forcing. We follow the approach stated in Hansen et al. (2007) that "a forcing is an imposed change of the planet's energy balance with space" and are concerned with "an empirical climate sensitivity [that] corresponds to the Charney (1979) definition of climate sensitivity, in which "fast feedback" processes are allowed to operate, but long-lived atmospheric gases, ice sheet area, land area and vegetation cover are (considered as) fixed forcings. Fast feedbacks include changes of water vapor, clouds, climate-driven aerosols, sea ice, and snow cover." Similar to Köhler et al. (2010) we also include an explicit determination of the forcing due to atmopheric dust variability. This could be debated because aerosol effects are not a slow feedback with a time scale of $10^{3} \mathrm{yr}$ like the carbon cycle and ice sheet size, but they are not fast like hydrological cycle (cloud, vapor) or sea ice feedbacks either; soil cohesion (and thus ablation potential) is not only a function of the fast adjusting hydrological cycle, but also of slow adjusting vegetation changes. For the latter reason, because we study orbital time-scale changes, we choose to explicitly resolve the aerosol (dust) feedback influences and to then a posteriori consider how our conclusion about climate sensitivity would change if dust were treated as a fast feedback instead. Thus, we explicitly account for the long-term (equilibrium) radiative impacts of greenhouse gas concentrations, ice sheet albedo, and atmospheric-dust-related albedo as "forcings," even though we acknowledge that all of these terms ultimately are feedbacks to the only true external forcing (insolation) so that "actual climate sensitivity (to greenhouse gas forcing) is much greater than that due to fast feedbacks (Hansen et al. 2007)." In specific terms, we consider a system in which there is external radiative forcing $Q_{\text {ext }}$ and temperature-related endogenous (feedback) forcing $Q_{\mathrm{fb}}$ (see, for example, Lemoine 2010), which is the temperature change $\Delta T$ times feedback sensitivity $g$ ( $\mathrm{W} \mathrm{m}^{-2}{ }^{\circ} \mathrm{C}^{-1}$ ), so that net forcing $\Delta F_{\text {tot }}$ is given by

$$
\Delta F_{\text {tot }}=Q_{\text {ext }}+Q_{\mathrm{fb}},
$$

where $Q_{\mathrm{fb}}=g \Delta T$. In our study, $Q_{\text {ext }}=\Delta F_{\text {ins }}$ (the radiative forcing due to insolation changes) while $Q_{\mathrm{fb}}$ is explicitly determined as the sum of the radiative impacts of 
changes in ice-sheet area albedo, greenhouse gas concentrations, and atmospheric dust loading (i.e., $Q_{\mathrm{fb}}=\Delta F_{\mathrm{alb}}+$ $\left.\Delta F_{\text {ghg }}+\Delta F_{\mathrm{du}}\right)$. Temperature change then is related to net forcing via a sensitivity factor $s\left[{ }^{\circ} \mathrm{C}\left(\mathrm{W} \mathrm{m}^{-2}\right)^{-1}\right]$, according to

$$
\Delta T=s \Delta F_{\text {tot }} .
$$

Hence,

$$
\Delta T=Q_{\text {ext }} s /(1-s g) .
$$

Our approach is warranted because of the long (orbital) time scales of the changes considered in our study. Estimation of $g$ remains problematic because of the potential for long (state-dependent) lags in the responses of slow feedback processes to forcing, and we therefore do not emphasize our findings for $g$ because they may be of little use for generalized statements. We then compare the total (equilibrium) radiative forcing changes with the overall (equilibrium) surface temperature responses. Initially, only those forcing functions are considered for which a sufficient understanding exists based on highquality time series of data, and next the maximum potential impact is evaluated of any less well-constrained effects that were initially omitted.

We consider two end-member scenarios for the distribution of radiative forcing. The first uses global mean values for all processes considered. This would be appropriate if the energy redistribution due to atmospheric and oceanic circulation had enough time within the resolution of the records to cause a global homogenization. The second scenario uses more regionally specific forcing changes based on zonal means for $10^{\circ}$ latitude bands. This would be appropriate if there were no/very little homogenization so that temperature at any site would be a reflection of the regional radiative balance. These are extreme end-member scenarios. In reality, the degree of energy redistribution is intermediate and likely changes as circulation changes through time, which could only be approximated through — yet unattainable—runs over multiple glacial cycles with fully coupled ocean-atmosphere general circulation models that at least include dynamic ice sheets, a comprehensive carbon cycle, a global dust cycle, and good cloud physics. Therefore, we simply present the two end-member extreme scenarios and evaluate the results accordingly. Using this approach, we are able to highlight regions where temperature sensitivity was higher or lower than the global mean per unit change in the radiative balance (i.e., $\varphi>1$ or $\varphi<1$ ), which highlights key mechanisms of energy redistribution and/or overlooked (or underestimated) processes of forcing.

Section 2 introduces the temperature records used. Section 3 develops records of radiative forcing change in a globally averaged sense, and section 4 compares this (with uncertainties) with our global compilation of temperature records, in a similar way as done previously for only Antarctic temperature (Hansen et al. 2007, 2008; Köhler et al. 2010). Next, section 5 considers the spatially inhomogeneous distribution of the impacts of the various forcing functions by determining zonal mean radiative forcing in $10^{\circ}$ latitude bands and compares each temperature response record with the radiative forcing record applicable for its latitude band. Finally, section 6 discusses key implications of the results.

\section{Records of temperature change}

While previous studies (Hansen et al. 2007, 2008; Köhler et al. 2010; Masson-Delmotte et al. 2010a) exclusively or primarily used Antarctic ice-core temperature data, we broaden the approach to consider a global suite of oceanic sea surface temperature (SST) records, from the archives of the World Data Center for Marine Environmental Sciences (WDC-MARE) and NOAA-Paleoclimatology (Fig. 1; metadata in Table 1). We only use records that have been finalized, published, and (critically) made publicly accessible from servers that are easy to locate, which ensures that anyone can easily reproduce and improve our conclusions. We also include the Greenland Ice Sheet Project 2 (GISP2) summit palaeotemperature record (based on the temperature calibration of Alley 2000) and the Antarctic temperature anomaly record of the European Project for Ice Coring in Antarctica (EPICA) Dome C (EDC) ice core (Jouzel et al. 2007). New temperature calibrations and temperature proxy records have been published for Greenland (e.g., Masson-Delmotte et al. 2005; Vinther et al. 2009a; Capron et al. 2010), but no continuous time series over the time period of interest of such improved temperature estimates is available (yet) from public data servers, which has precluded them from inclusion in this study (see also section 6).

The temperature records were selected on the basis of continuity through (almost) a glacial cycle or longer. We thus aim to highlight the basic underlying (longer term) and repeatable temperature variations relative to changes in climate forcing, rather than emphasizing the impacts of noise and/or short-term variability, which would be an issue if short time series or individual time slices were selected. Our approach thus suppresses event-specific bias and, instead, emphasizes the common aspects of temperature response to climate forcing between episodes such as different glacial states. The disadvantage of our time-span requirement is that it limits the number of available records, but we are able to obtain adequate data coverage for this first-order evaluation, which is the first of its kind (Fig. 1). 


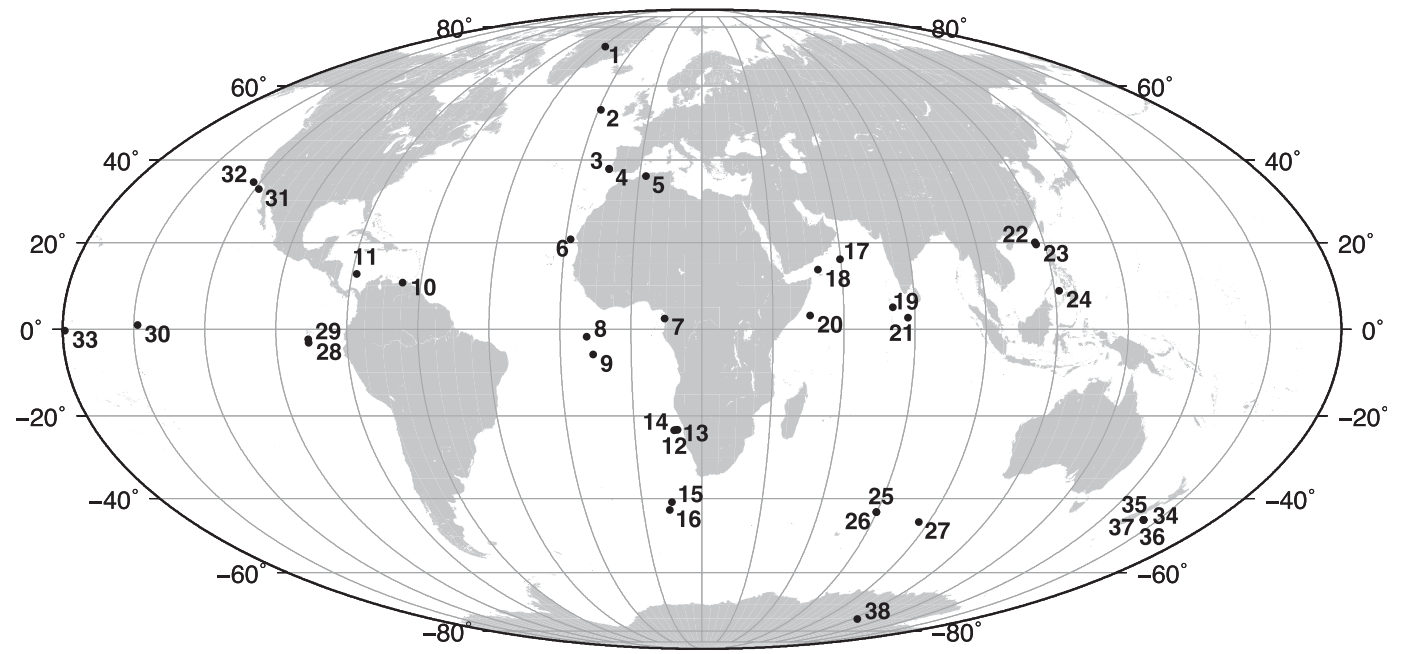

FIG. 1. Geographic distribution of the temperature reconstructions used in this study.

We do not include terrestrial records other than the icecore records because of their high potential variability and possible bias due to seasonal and meso/microclimate effects. Although some seasonal bias may still occur, ocean temperature is inherently much less variable. Chronologies for the records were used as reported, without "tuning," except in some cases for some basic adjustment to ensure that major transitions were more-or-less synchronous (records 11, 15, 16, 26, 27, 30, 34, and 35; tables with tie-points used for these adjustments are released along with other datasets for this study through websites given in the acknowledgments). All records are considered in terms of relative variability (see below) and interpolated to the time steps of the sea level record to bring everything into the same format with a common chronology.

It is evident from Fig. 1 that the available SST records have an approximately global distribution, but also that there are substantial blank areas in the map that would be excellent targets for future development of high-quality SST records. There are evident limitations with certain proxies for SST reconstruction that result in some very noisy datasets (especially numbers 16 and 34) (Fig. 2). Also, different proxies applied to the same site can result in different results (e.g., numbers 35, 36, and 37), which may be due to different seasonal and/or ecological biases (MARGO project members 2009). Multiple replicates of SST proxy analyses enable comparison of relative fluctuations within a single record and typically reveal a mean standard error of about $\pm 0.5^{\circ} \mathrm{C}$, but we consider it prudent to allow a wider error margin of $\pm 1^{\circ} \mathrm{C}$ to better allow for differences between records (Rohling 2007; MARGO project members 2009).

It is important to emphasize that we compare our global set of temperature records with reconstructed time series of radiative forcing (sections 3 and 5) entirely in terms of variations (differences relative to reference values), rather than absolute values. Therefore, records that extend sufficiently close to the present are referenced to their AD1000 value, and records that terminate at more distant points in time are referenced to their youngest value. Although for convenience we reference all records to single time points, referencing to a mean over the preceding 500 years in the records used gives the same result, well within $0.5^{\circ} \mathrm{C}$ for the marine records and typically $1^{\circ} \mathrm{C}$ for ice-core records (for overviews of recent-centuries variability in ice cores, see Goosse et al. 2004; Vinther et al. $2009 b)$. These differences are small with respect to the large-scale glacial-interglacial variability that we focus on, but also - crucially — we exclusively consider relative fluctuations so that our conclusions are completely unaffected by the choice of referencing method.

\section{Global mean radiative forcing reconstruction with uncertainties}

High-resolution records of changes in the radiative forcing of climate over several glacial cycles are calculated in similar ways as in previous studies (Hansen et al. 2007, 2008; Köhler et al. 2010), from Antarctic ice-core records for atmospheric $\mathrm{CO}_{2}$ (Siegenthaler et al. 2005), $\mathrm{CH}_{4}$ (Loulergue et al. 2008), and dust concentrations (Lambert et al. 2008). We complement these by a similarly detailed, continuous record of sea level fluctuations over the last five glacial cycles (Siddall et al. 2003; Rohling et al. 2009, 2010), from which we calculate the radiative impacts of changes in ice sheet albedo following Hansen et al. (2007, 2008). The combined dataset portrays the global mean radiative forcings of climate due to greenhouse gas (GHG) concentrations and due to albedo changes related to ice sheet area and atmospheric dust concentrations (Fig. 3). 
TABLE 1. Metadata for the temperature records compiled in this paper: modern analog technique (MAT) and transfer function (TF).

\begin{tabular}{|c|c|c|c|c|c|c|}
\hline Number & Site & Lat & Lon & Region & Technique & References \\
\hline 1 & GISP2 & 72.60 & -38.50 & Greenland Summit & Oxygen isotope ratio ice & $\begin{array}{l}\text { Grootes et al. (1993), } \\
\quad \text { Alley (2000) }\end{array}$ \\
\hline 2 & GIK23415-9 & 53.18 & -19.15 & North Atlantic & MAT planktonic forams & Weinelt et al. (2003) \\
\hline 3 & MD95-2042 & 37.80 & -10.17 & Iberian Margin & Alkenones Uk'37 & Pailler and Bard (2002) \\
\hline 4 & SU81-18 & 37.77 & -10.18 & Iberian Margin & Alkenones Uk'37 & Bard (2002), Bard et al. (2004) \\
\hline 5 & ODP 161-977A & 36.03 & 1.96 & Alboran Sea & Alkenones Uk'37 & Martrat et al. (2009) \\
\hline 6 & ODP $658 \mathrm{C}$ & 20.75 & -18.58 & Off NW Africa & Alkenones Uk’37 & $\begin{array}{l}\text { Zhao et al. (1995), } \\
\text { deMenocal et al. } \\
(2000), \text { Adkins et al. (2006) }\end{array}$ \\
\hline 7 & MD03-2707 & 2.50 & 9.40 & Gulf of Guinea & $\mathrm{Mg} / \mathrm{Ca}$ & Weldeab et al. (2007) \\
\hline 8 & GeoB-1105 & -1.67 & -12.43 & $\begin{array}{l}\text { Eastern equatorial } \\
\text { Atlantic }\end{array}$ & $\mathrm{Mg} / \mathrm{Ca}$ & Nuernberg et al. (2000) \\
\hline 9 & GeoB-1112 & -5.77 & -10.75 & $\begin{array}{l}\text { Eastern equatorial } \\
\text { Atlantic }\end{array}$ & $\mathrm{Mg} / \mathrm{Ca}$ & Nuernberg et al. (2000) \\
\hline 10 & ODP Hole 165-1002C & 10.71 & -65.17 & Cariaco & Alkenones Uk'37 & Herbert and Schuffert (2000) \\
\hline 11 & ODP Hole 165-999A & 12.74 & -78.74 & Caribbean & $\mathrm{Mg} / \mathrm{Ca}$ & Schmidt et al. (2004) \\
\hline 12 & GeoB1710-3 & -23.43 & 11.70 & Benguela Current & Alkenones Uk'37 & Kirst et al. (1999) \\
\hline 13 & GeoB1711-4 & -23.32 & 12.38 & Benguela Current & Alkenones Uk'37 & Kirst et al. (1999) \\
\hline 14 & GeoB1712-4 & -23.26 & 12.81 & Benguela Current & Alkenones Uk'37 & Kirst et al. (1999) \\
\hline 15 & ODP Site $177-1089$ & -40.94 & 9.89 & Subantarctic Atlantic & TF radiolaria & Cortese et al. (2007) \\
\hline 16 & PS2489-2 & -42.87 & 8.97 & Subantarctic Atlantic & MAT diatoms & Becquey and Gersonde (2003) \\
\hline 17 & GeoB3007-1 & 16.17 & 59.76 & Western Arabian Sea & Alkenones Uk'37 & Budziak (2001) \\
\hline 18 & Т93-929 & 13.70 & 53.25 & Western Indian & Alkenones Uk'37 & Rostek et al. (1997) \\
\hline 19 & MD90-963 & 5.07 & 73.88 & Western Indian & Alkenones Uk'37 & Rostek et al. (1993) \\
\hline 20 & MD85-674 & 3.18 & 50.43 & Western Indian & Alkenones Uk’37 & Bard et al. (1997) \\
\hline 21 & SK $157 / 4$ & 2.67 & 78.00 & Equatorial Indian & $\mathrm{Mg} / \mathrm{Ca}$ & Saraswat et al. (2005) \\
\hline 22 & ODP Hole 184-1144A & 20.05 & 117.42 & $\begin{array}{l}\text { Northern South } \\
\text { China Sea }\end{array}$ & $\mathrm{Mg} / \mathrm{Ca}$ & Wei et al. (2007) \\
\hline 23 & ODP $1841145 \mathrm{C}$ & 19.58 & 117.63 & $\begin{array}{l}\text { Northern South } \\
\text { China Sea }\end{array}$ & $\mathrm{Mg} / \mathrm{Ca}$ & Oppo and Sun (2005) \\
\hline 24 & MD97-2141 & 8.78 & 121.28 & Sulu Sea & $\mathrm{Mg} / \mathrm{Ca}$ & Rosenthal et al. (2003) \\
\hline 25 & RC11-120 & -43.52 & 79.87 & Subantarctic Indian & $\mathrm{Mg} / \mathrm{Ca}$ & Rickaby and Elderfield (1999) \\
\hline 26 & RC11-120 & -43.52 & 79.87 & Subantarctic Indian & $\mathrm{Mg} / \mathrm{Ca}$ & Mashiotta et al. (1999) \\
\hline 27 & MD88-770 & -46.02 & 96.47 & Subantarctic Indian & $\mathrm{Mg} / \mathrm{Ca}$ & Rickaby and Elderfield (1999) \\
\hline 28 & ODP846 & -3.10 & -90.82 & $\begin{array}{l}\text { Eastern equatorial } \\
\text { Pacific }\end{array}$ & Alkenones Uk'37 & Lawrence et al. (2006) \\
\hline 29 & TR163-19 & -2.26 & -90.95 & $\begin{array}{l}\text { Eastern equatorial } \\
\text { Pacific }\end{array}$ & $\mathrm{Mg} / \mathrm{Ca}$ & Lea et al. (2000) \\
\hline 30 & W8402A-14 & 0.95 & -138.96 & $\begin{array}{l}\text { Central equatorial } \\
\text { Pacific }\end{array}$ & Alkenones Uk'37 & Jasper et al. (1994) \\
\hline 31 & ODP $1014 \mathrm{a}$ & 32.80 & -118.90 & California Current & Alkenones Uk'37 & Yamamoto et al. (2007) \\
\hline 32 & ODP $1016 \mathrm{c}$ & 34.53 & -122.28 & California Current & Alkenones Uk'37 & Yamamoto et al. (2007) \\
\hline 33 & ODP 806B & -0.32 & -159.36 & Equatorial Pacific & $\mathrm{Mg} / \mathrm{Ca}$ & Lea et al. (2000) \\
\hline 34 & DSDP Site $90-594$ & -45.52 & 174.95 & $\begin{array}{l}\text { South Pacific } \\
\text { continental rise }\end{array}$ & MAT planktonic forams & Schaefer et al. (2005) \\
\hline 35 & MD97-2120 & -45.53 & 174.93 & Chatham Rise & $\mathrm{Mg} / \mathrm{Ca}$ & Pahnke et al. (2003) \\
\hline 36 & MD97-2120 & -45.53 & 174.93 & Chatham Rise & Alkenones Uk'37 & Pahnke and Sachs (2006) \\
\hline 37 & MD97-2120 & -45.53 & 174.93 & Chatham Rise & Alkenones Uk'37 & Pahnke and Sachs (2006) \\
\hline 38 & EPICA Dome C & -75.10 & 123.35 & Antarctica & Hydrogen isotope ratio ice & Jouzel et al. (2007) \\
\hline
\end{tabular}

The atmospheric $\mathrm{CO}_{2}$ and $\mathrm{CH}_{4}$ records are converted into radiative forcing $\left(\Delta F_{\mathrm{CO} 2}\right.$ and $\Delta F_{\mathrm{CH} 4}$ in watts per square meter) using equations specified in the Intergovernmental Panel on Climate Change third assessment report (Houghton et al. 2001) (appendix A). From these we derive the total radiative forcing from GHG concentration changes $\Delta F_{\mathrm{GHG}}$ (Fig. 2) following the approach of
Hansen et al. (2008) (appendix A). Uncertainties to $\Delta F_{\mathrm{GHG}}$ (Fig. 2) are discussed below.

The new sea level record allows us to evaluate changes in the radiative forcing of climate due to ice-sheet-area-

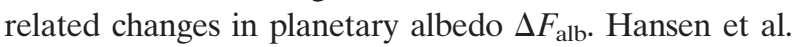
(2008) established that $\Delta F_{\text {alb }}$ can be approximated using a linear relationship (appendix A) with a slope of $0.0308 \mathrm{~W} \mathrm{~m}^{-2}$ 
(a)

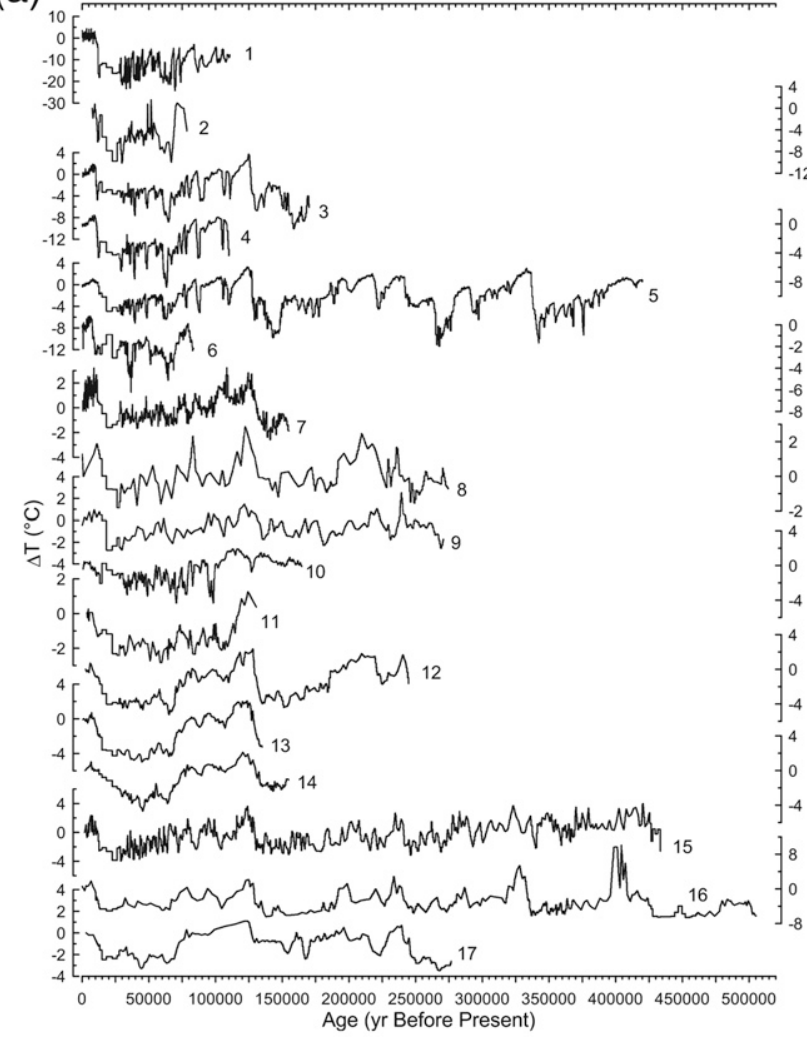

(b)

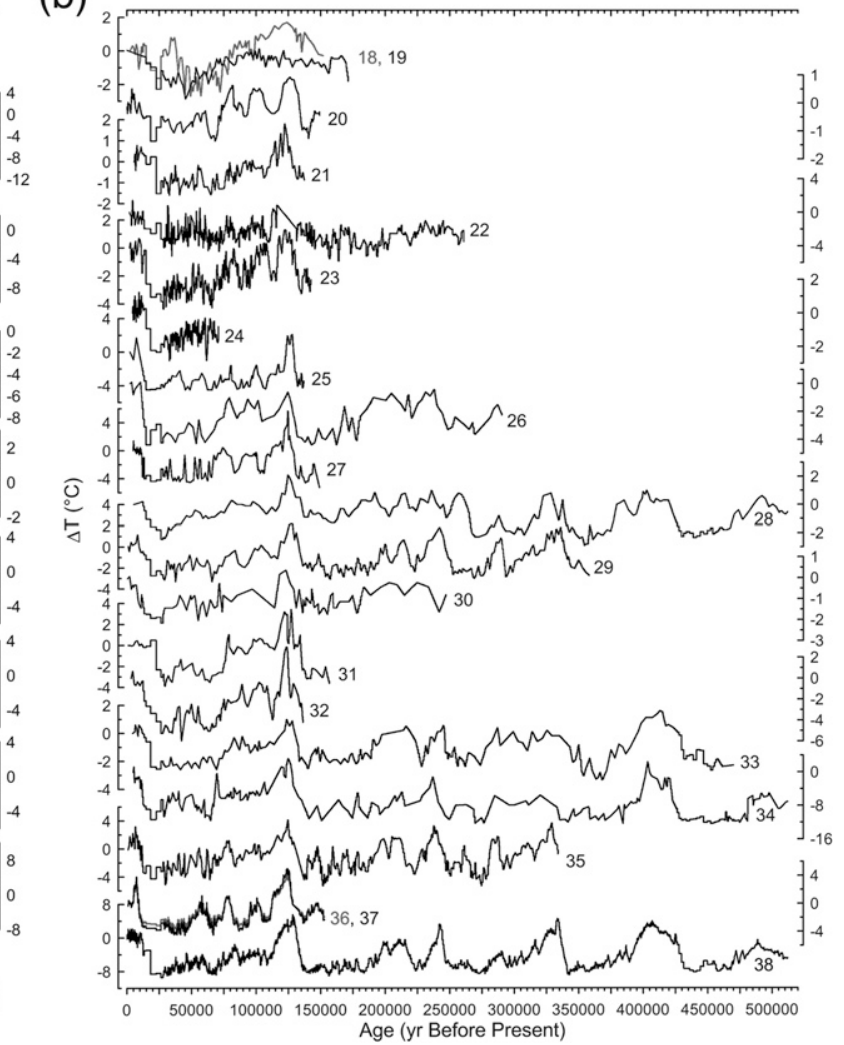

FIG. 2. (a) Step-plot representations of the records of relative temperature change used in the present study, numbers 1-17. To bring all records into a single, directly comparable framework, all records have been interpolated onto time steps of the relative sea level record on its U-h-adjusted chronology (Rohling et al. 2010). Numbers refer to those in Figs. 5a,b and Tables 1 and 2. (b) As in (a) but for numbers 18-38.

per meter of sea level (SL) change (Fig. 3). As a test, we also explored a case where $\Delta F_{\text {alb }}$ is related to ice volume in a nonlinear manner (Hansen et al. 2008) (appendix A). Because Fig. 3 demonstrates that both solutions are virtually identical, we continue using only the linear relationship.

We obtain $\Delta$ SL from the recent high-resolution Red Sea sea level record with a $1 \sigma$ uncertainty of $\pm 6.5 \mathrm{~m}$ (Rohling et al. 2009) (Fig. 3). The method by which that record was derived relies on robust physical assumptions behind the hydraulic equations, which conserve energy and volume along the strait (Siddall et al. 2003, 2004). The method has been extensively tested and validated, including by agreement with the results from a completely different (numerical) approach (Biton et al. 2008). The sea level reconstructions from this method agree within the uncertainty with traditional sea level benchmark measurements around the world from independent techniques (see Rohling et al. 2008, 2009, 2010; Siddall et al. 2008, and references therein). Further details about the method and its validations can be found in Siddall et al. (2003, 2004) and Rohling et al. (2009, 2010).

The Red Sea sea level record was recently expressed on a new chronology that constrains the orbital time-scale variability within $\pm 1.5 \%$ (age) uncertainty of radiometrically dated sea level benchmarks (Rohling et al. 2010). This agreement is also valid for the new benchmark data of Andersen et al. (2010) and the new synthesis for the last deglaciation by Stanford et al. (2011). On orbital time scales, the new sea level chronology is now independent of that of the ice-core records, and from any "astronomical time scale tuning." Nonindependent chronology is a problem for all previously used sea level reconstructions, based primarily on deep sea stable oxygen isotope records, so our chronological independence represents a significant improvement. Figure 4 shows a comparison between the time series of physically more direct Red Sea sea level data and previous continuous sea level deconvolutions from indirect proxy methods. Uncertainties to $\Delta F_{\text {alb }}$ (Fig. 3) are discussed below.

It remains hard to quantify global climate forcing due to atmospheric albedo changes as related to atmospheric dust loading $\Delta F_{\mathrm{du}}$. This is mainly because of a lack of global dust flux information. To date, the only long and highly resolved record of atmospheric dust flux is from the Antarctic EPICA Dome C (EDC) ice core (Lambert et al. 2008). Similarity of fluctuations in the signal with 


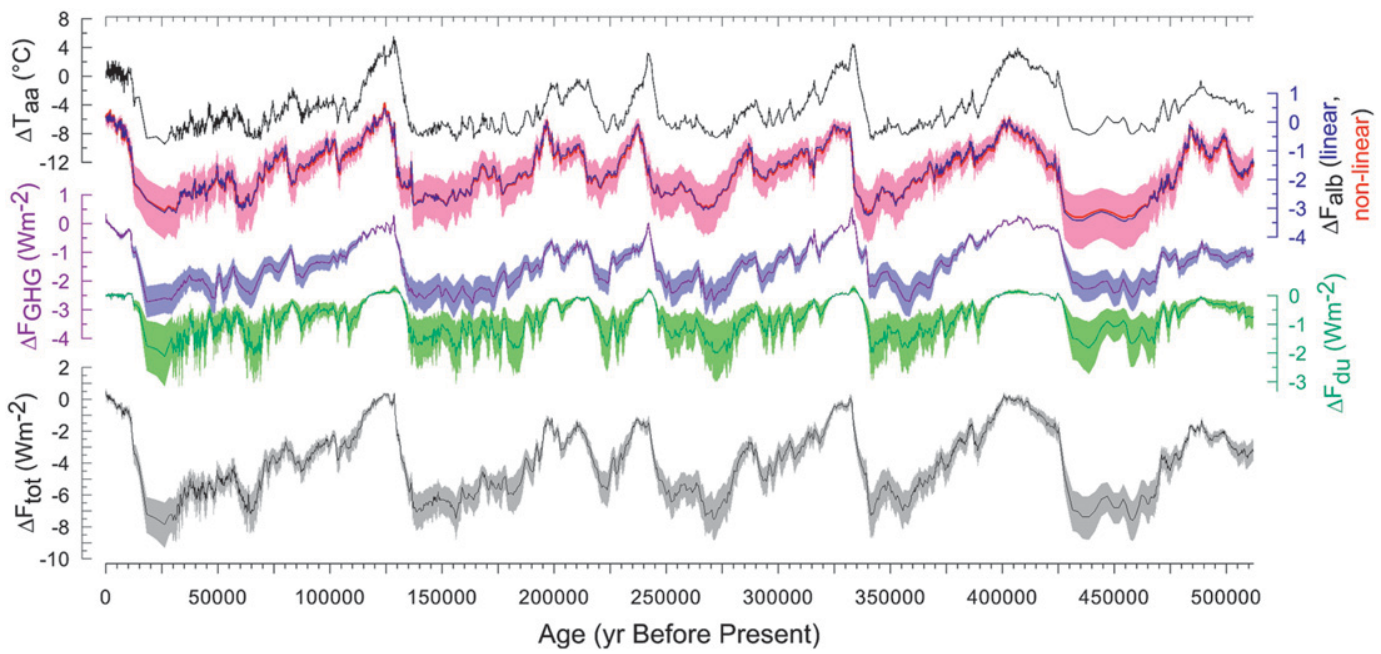

FIG. 3. Records of Antarctic temperature anomaly $\Delta T_{\text {aa }}$ determined for the EPICA Dome C ice core (Jouzel et al. 2007) and of global means for the main radiative climate forcing functions due to ice sheet albedo $\Delta F_{\text {alb }}$, greenhouse gas concentrations $\Delta F_{\mathrm{GHG}}$, and atmospheric-dust-related albedo $\Delta F_{\mathrm{du}}$. Forcing records and uncertainties (shaded intervals) calculated as described in the text: $\Delta F_{\text {alb }}$ has been calculated using a linear transformation (blue) and a nonlinear transformation (red) from the sea level record of Rohling et al. $(2009,2010)$ as detailed in the text; $\Delta F_{\text {tot }}$ represents the global mean total forcing reconstruction from the above components, with cumulative uncertainties.

those in the dust fluxes reconstructed for the equatorial Pacific (Winckler et al. 2008) suggests that the EDC record may serve as a first-order indicator of global, orbital time-scale, atmospheric dust fluctuations, but the level of agreement really is only sufficient to say that glacials were dusty and interglacials were less dusty. With respect to higher temporal resolutions, it seems unlikely that the Southern Hemisphere processes causing the dust fluxes at EDC would still give a close representation of global atmospheric dust loading because major impacts would be expected from the large expanse of deserts and general continentality on the Northern Hemisphere (e.g., Moreno et al. 2002; Larrasoaña et al. 2003; Rohling et al. 2003). Good-quality, high-resolution dust records are needed downwind from all of the world's major dust sources before any more conclusive interpretations can be formulated. For the time being, we consider the dust influences in a similar manner as Köhler et al. (2010) from the EDC data. We use

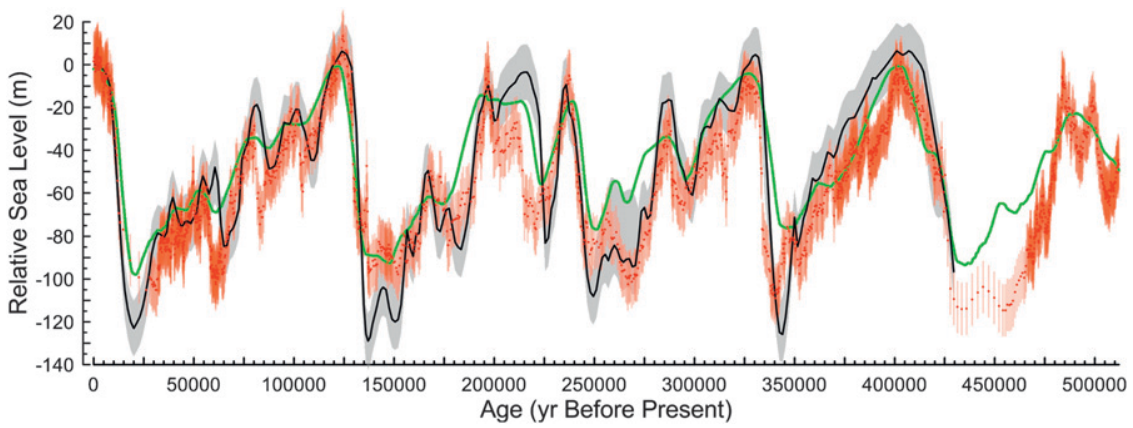

FIG. 4. Comparison between three approaches for continuous sea level reconstruction. Black is Waelbroeck et al. (2002) based on coral-calibrated deep sea benthic $\delta^{18} \mathrm{O}$, with uncertainties (gray). Green is the reconstruction of De Boer et al. (2010) from a model-based deconvolution of benthic $\delta^{18} \mathrm{O}$ records into a temperature and a sea level component; an evolution of the work of Bintanja et al. (2005) that was used in Köhler et al. (2010) and Masson-Delmotte et al. (2010a). Red dots with orange $(2 \sigma)$ uncertainty bars represent the Red Sea reconstruction on its U-Th adjusted chronology (Rohling et al. 2009, 2010). It is evident that, within uncertainties, there is a good general agreement between the Waelbroeck et al. (2002) and Red Sea reconstructions, but that the De Boer et al. (2010) reconstruction is only roughly comparable and lacks important variability and amplitude. Chronology of the De Boer et al. (2010) reconstruction is astronomically tuned. That of Waelbroeck et al. (2002) is also orbitally tuned, but it has been adjusted to account for U-Th dated corals. 

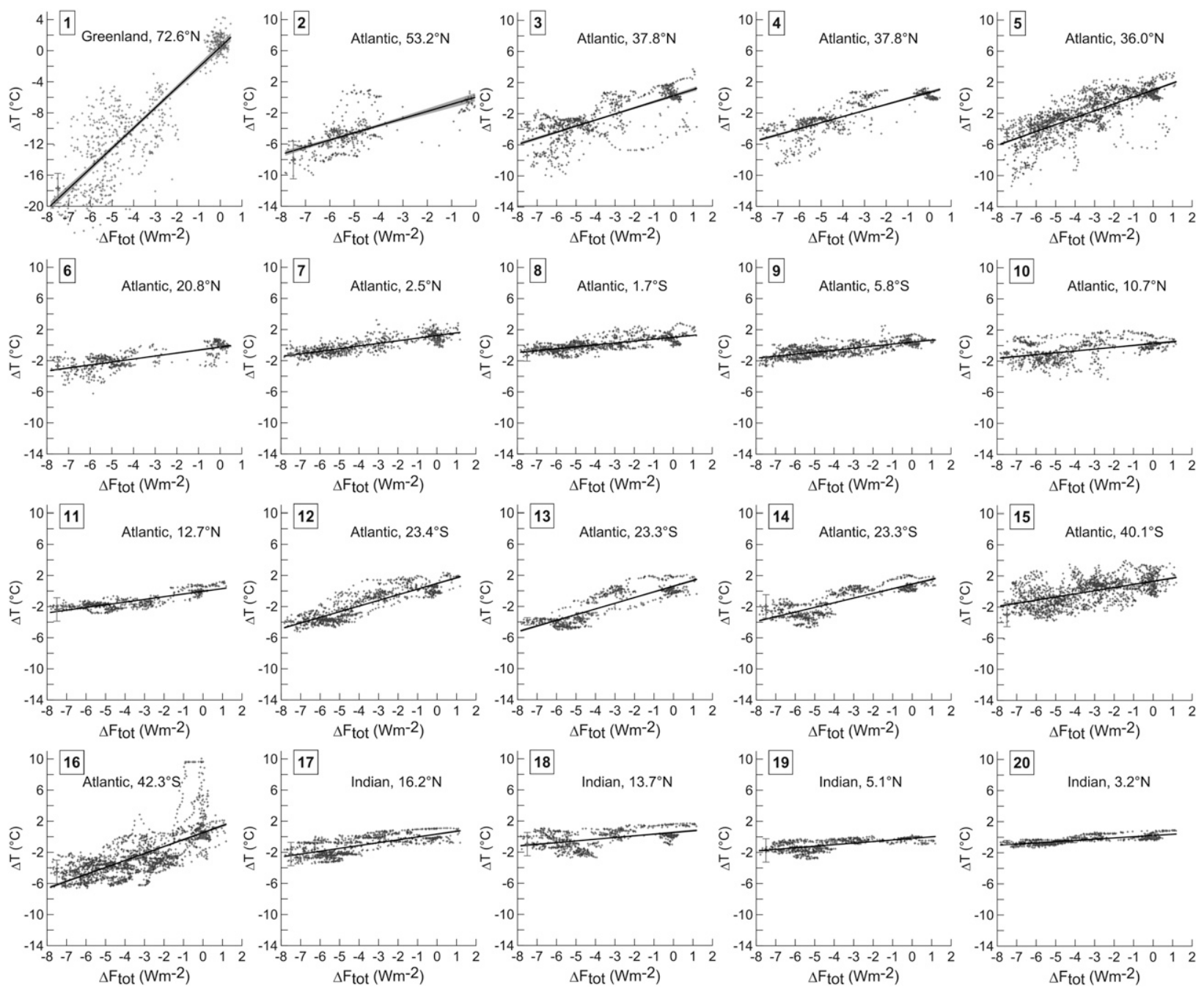

FIG. 5a. (a) Linear regressions between $\Delta F_{\text {tot }}$ (global mean) and relative temperature change for the various locations studied here, numbers 1-20. Shading denotes $95 \%$ confidence limits to the fitted linear regressions (i.e., for the fit itself, not for data around the fit). Numbers correspond to descriptions in Tables 1 and 2.

a simple linear scaling between the LGM and present differences in the $\log _{10}$ (see Köhler et al. 2010) of the dust flux $\chi$ and its radiative forcing impact $\left(12 \mathrm{mg} \mathrm{m}^{-2} \mathrm{yr}^{-1}\right.$ (Lambert et al. 2008), and $-1.9 \mathrm{~W} \mathrm{~m}^{-2}$ (Köhler et al. 2010), respectively), with generous uncertainty limits (Fig. 3):

$$
\Delta F_{\mathrm{du}}=-1.9 \log _{10}(\Delta \chi) .
$$

The combined explicitly determined radiative forcing is calculated by adding up the individual terms (Fig. 3):

$$
\Delta F_{\text {tot }}=\Delta F_{\mathrm{GHG}}+\Delta F_{\mathrm{alb}}+\Delta F_{\mathrm{du}}+\Delta F_{\mathrm{ins}},
$$

where in the global mean scenario $\Delta F_{\text {ins }}$ is negligible relative to the other terms (Hansen et al. 2007, 2008).

The uncertainties we consider in the relationships used to calculate climate forcing from the various observed properties (Fig. 3) are estimated to be $\pm 50 \%$ in $\Delta F_{\mathrm{du}}$ (based on the uncertainty to the LGM value for dust forcing in Köhler et al. 2010) and $\pm 20 \%$ in $\Delta F_{\mathrm{GHG}}$ and $\Delta F_{\text {alb. }}$. In addition to the $\pm 20 \%$ uncertainty in the calculation of $\Delta F_{\text {alb }}$ from the sea level record, we have also first accounted for a \pm 6.5 -m uncertainty in the sea level values (Siddall et al. 2003, 2004; Rohling et al. 2009) when showing the uncertainty envelopes in Fig. 3, as this is a realistic range in comparison with independent sea level benchmark data. The $20 \%$ margins on $\Delta F_{\mathrm{GHG}}$ represent generous margins based on previous assessments (Collins et al. 2006; Solomon et al. 2007; Köhler et al. 2010). Error propagation gives an overall uncertainty of $\pm 1.5 \mathrm{~W} \mathrm{~m}^{-2}$, up to a maximum of $1.75 \mathrm{~W} \mathrm{~m}^{-2}$, over the full range of $\Delta F_{\text {tot }}$ changes (Fig. 3). Because of an emphasis to err on the cautious side and the unknown character of some of the uncertainties (e.g., for dust), the overall uncertainties 

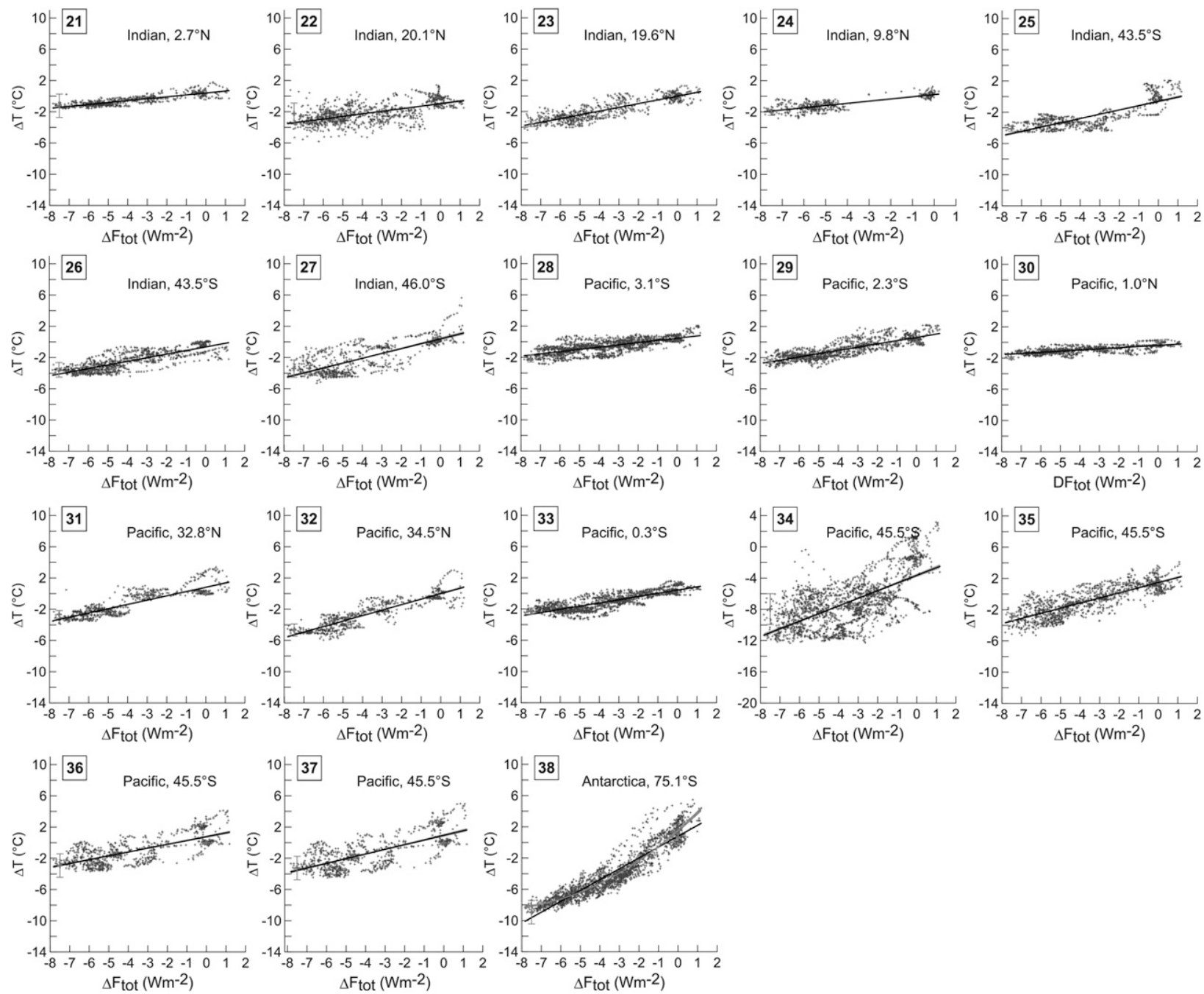

FIG. 5b. As in (a), but for numbers 21-38. Red fit in number 38 is a quadratic fit that highlights the fundamentally nonlinear relationship in this particular plot, as discussed in section 6 .

are deliberately conservative approximations of $95 \%$ confidence limits.

The above analysis implies an uncertainty of up to $\pm 25 \%$ in the slope of the regression of temperature response versus radiative forcing. A large element of that uncertainty is systematically consistent (i.e., if the forcing calculation based on greenhouse gas concentrations or sea level is in error, then it is systematically so for all records), so relative differences in the regression slope values are more robust than the absolute magnitude of the uncertainty envelope would suggest.

\section{Comparison of temperature response records with global mean forcing changes}

Global mean $\Delta F_{\text {tot }}$ is regressed against the different (local) temperature records (Fig. 5) to determine linear regression slopes that portray the mean long-term linear temperature response (the primary mode of temperature sensitivity, hereafter $\Omega=\Delta T_{\text {loc }} / \Delta F_{\text {tot }}\left[{ }^{\circ} \mathrm{C}\left(\mathrm{W} \mathrm{m}^{-2}\right)^{-1}\right]$ (Table 2). Note that absolute values, including axis intercepts, are irrelevant because of the referencing procedure applied to all records.

To evaluate whether disequilibrium due to ocean thermal inertia affects the regression results, we have run $\Delta F_{\text {tot }}$ through the Model for the Assessment of Greenhouse-Gas Induced Climate Change (MAGICC) energy balance model (as specified in appendix A of Eickhout et al. 2004) and found that the estimates of the regression slopes with global mean temperature are within $1 \%$ of the prescribed model climate sensitivity. This is unsurprising given that the multimillennial time scale of the palaeodata is significantly longer than the time scales associated with ocean heat equilibration (Jarvis and Li 2011). This result also highlights that the estimates of $\Omega$ obtained from the 
TABLE 2. Regression statistics for the linear regressions shown in Fig. 5. Columns are SSR: regression sum of squares, MSR =SSR/1; SSE: residual sum of squares; MSE $=\mathrm{SSE} / n-2 ; F$ statistic $=$ MSR/MSE at $(1, n-2)$ degrees of freedom; RMSE: root-mean-square error; $r^{2}=$ $\mathrm{SSR} /(\mathrm{SSR}+\mathrm{SSE})$; The critical $F$ value for significance at $P=0.01$ with $(1, n-2)$ degrees of freedom is about 7 for all cases.

\begin{tabular}{|c|c|c|c|c|c|c|c|c|c|}
\hline Number & Slope & $N$ & SSR & SSE & MSR & MSE & $F$ statistic & RMSE & $r^{2}$ \\
\hline 1 & 2.60 & 632 & 24825.90 & 7523.75 & 24825.90 & 11.94 & 2079 & 3.46 & 0.77 \\
\hline 2 & 0.92 & 403 & 1018.93 & 1346.47 & 1018.93 & 3.36 & 303 & 1.83 & 0.43 \\
\hline 3 & 0.78 & 832 & 3244.21 & 2829.26 & 3244.21 & 3.41 & 952 & 1.85 & 0.53 \\
\hline 4 & 0.78 & 630 & 2225.04 & 1073.65 & 2225.04 & 1.71 & 1301 & 1.31 & 0.67 \\
\hline 5 & 0.89 & 1668 & 6967.87 & 4531.83 & 6967.87 & 2.72 & 2562 & 1.65 & 0.61 \\
\hline 6 & 0.38 & 541 & 530.05 & 417.53 & 530.05 & 0.77 & 684 & 0.88 & 0.56 \\
\hline 7 & 0.34 & 797 & 584.75 & 315.87 & 584.75 & 0.40 & 1472 & 0.63 & 0.65 \\
\hline 8 & 0.25 & 1061 & 366.34 & 372.97 & 366.34 & 0.35 & 1040 & 0.59 & 0.50 \\
\hline 9 & 0.26 & 1054 & 402.97 & 343.50 & 402.97 & 0.33 & 1234 & 0.57 & 0.54 \\
\hline 10 & 0.24 & 816 & 294.54 & 1091.43 & 294.54 & 1.34 & 220 & 1.16 & 0.21 \\
\hline 11 & 0.35 & 655 & 450.04 & 185.63 & 450.04 & 0.28 & 1583 & 0.53 & 0.71 \\
\hline 12 & 0.73 & 967 & 2739.28 & 901.13 & 2739.28 & 0.93 & 2933 & 0.97 & 0.75 \\
\hline 13 & 0.73 & 731 & 2434.27 & 868.74 & 2434.27 & 1.19 & 2043 & 1.09 & 0.74 \\
\hline 14 & 0.60 & 765 & 1663.95 & 768.70 & 1663.95 & 1.01 & 1652 & 1.00 & 0.68 \\
\hline 15 & 0.41 & 1664 & 1411.22 & 2942.48 & 1411.22 & 1.77 & 797 & 1.33 & 0.32 \\
\hline 16 & 0.89 & 1987 & 7722.05 & 8291.76 & 7722.05 & 4.18 & 1849 & 2.04 & 0.48 \\
\hline 17 & 0.37 & 1015 & 721.46 & 732.60 & 721.46 & 0.72 & 998 & 0.85 & 0.50 \\
\hline 18 & 0.22 & 757 & 216.57 & 729.54 & 216.57 & 0.97 & 224 & 0.98 & 0.23 \\
\hline 19 & 0.20 & 837 & 217.67 & 249.04 & 217.67 & 0.30 & 730 & 0.55 & 0.47 \\
\hline 20 & 0.16 & 787 & 124.24 & 89.98 & 124.24 & 0.11 & 1084 & 0.34 & 0.58 \\
\hline 21 & 0.24 & 658 & 205.60 & 87.51 & 205.60 & 0.13 & 1541 & 0.37 & 0.70 \\
\hline 22 & 0.33 & 1008 & 581.85 & 1061.05 & 581.85 & 1.05 & 552 & 1.03 & 0.35 \\
\hline 23 & 0.48 & 730 & 1019.70 & 342.32 & 1019.70 & 0.47 & 2169 & 0.69 & 0.75 \\
\hline 24 & 0.28 & 425 & 178.57 & 112.18 & 178.57 & 0.27 & 673 & 0.51 & 0.61 \\
\hline 25 & 0.55 & 709 & 1253.66 & 687.79 & 1253.66 & 0.97 & 1289 & 0.99 & 0.65 \\
\hline 26 & 0.46 & 1072 & 1199.78 & 517.36 & 1199.78 & 0.48 & 2481 & 0.70 & 0.70 \\
\hline 27 & 0.62 & 709 & 1514.18 & 1108.07 & 1514.18 & 1.57 & 966 & 1.25 & 0.58 \\
\hline 28 & 0.29 & 1965 & 703.59 & 690.95 & 703.59 & 0.35 & 1999 & 0.59 & 0.50 \\
\hline 29 & 0.42 & 1291 & 1234.91 & 541.39 & 1234.91 & 0.42 & 2940 & 0.65 & 0.70 \\
\hline 30 & 0.15 & 1012 & 127.07 & 126.36 & 127.07 & 0.13 & 1016 & 0.35 & 0.50 \\
\hline 31 & 0.55 & 796 & 1532.94 & 488.58 & 1532.94 & 0.62 & 2491 & 0.78 & 0.76 \\
\hline 32 & 0.70 & 686 & 1922.19 & 464.00 & 1922.19 & 0.68 & 2834 & 0.82 & 0.81 \\
\hline 33 & 0.41 & 1672 & 1424.21 & 605.32 & 1424.21 & 0.36 & 3929 & 0.60 & 0.70 \\
\hline 34 & 0.98 & 1971 & 8243.42 & 11686.60 & 8243.42 & 5.94 & 1389 & 2.44 & 0.41 \\
\hline 35 & 0.66 & 1221 & 2864.87 & 1423.76 & 2864.87 & 1.17 & 2453 & 1.08 & 0.67 \\
\hline 36 & 0.49 & 787 & 1203.35 & 1080.85 & 1203.35 & 1.38 & 874 & 1.17 & 0.53 \\
\hline 37 & 0.60 & 787 & 1784.09 & 1602.53 & 1784.09 & 2.04 & 874 & 1.43 & 0.53 \\
\hline 38 & 1.39 & 2051 & 18676.10 & 2861.60 & 18676.10 & 1.40 & 13373 & 1.18 & 0.87 \\
\hline
\end{tabular}

palaeodata are dominated by the large, long time-scale perturbations in $\Delta F_{\text {tot }}$ and not by higher frequency, less significant, variations.

If we use a typical (stochastic) mean standard error of about $\pm 1^{\circ} \mathrm{C}$ for replicated analyses of temperature proxies such as those compiled here, then this translates to a random uncertainty of approximately $\pm 0.1^{\circ} \mathrm{C}\left(\mathrm{W} \mathrm{m}^{-2}\right)^{-1}$ in the regression slopes relative to the full range of the radiative forcing, which is additional to the possible uncertainty of up to $\pm 25 \%$ discussed above (most of which is systematic in the sense that all records are similarly affected). Köhler et al. (2010) suggest that additional, less understood, forcing factors would make the total glacialinterglacial $\Delta F_{\text {tot }}$ range closer to $10 \mathrm{~W} \mathrm{~m}^{-2}$, rather than the $8 \mathrm{~W} \mathrm{~m}^{-2}$ determined here from the major effects only.
This would again systematically affect all records in the same way, making the total systematic error in $\Omega$ more likely to be negative than positive (because a range adjustment in $\Delta F_{\text {tot }}$ from 8 to $10 \mathrm{~W} \mathrm{~m}^{-2}$ would be the same for all comparisons). At the positive extreme of error propagation, the possible uncertainties discussed above largely cancel out the effect of the likely range adjustment in $\Delta F_{\text {tot }}$, while at the negative extreme the two compound each other to produce a combined negative uncertainty of up to about $-40 \%$. We thus infer the most realistic interval for each $\Omega$ over the range $\left(0.6 \Omega_{\text {regr }}-0.1\right)<\Omega<$ $\left(\Omega_{\text {regr }}+0.1\right)$, where $\Omega_{\text {regr }}$ represents the slope of each individual regression in Fig. 5 and Table 2.

Next, we account for the influence on the regression slopes of the impact of the atmospheric lapse rate $\gamma$ on 
SST during times with lowered sea level (appendix A). Correction for the lapse rate effect causes a steepening of the regression lines that determine $\Omega$ in our marine sites. For $\Delta F_{\text {tot }}=-8$ or $-10 \mathrm{~W} \mathrm{~m}^{-2}$, this increases the regression slopes by 0.09 (or 0.07$)^{\circ} \mathrm{C}\left(\mathrm{W} \mathrm{m}^{-2}\right)^{-1}$, respectively. Thus we derive a final estimate for the most realistic range of about $\left(0.6 \Omega_{\text {regr }}\right)<\Omega<\left(\Omega_{\text {regr }}+0.2\right)$.

In the North Atlantic, including Greenland, the records (numbers 1-5) reveal enhanced variability around the regression, which is not an issue of proxy quality but a reflection of the strong abrupt climate changes within glacial intervals in that region (the so-called DansgaardOeschger cycles: e.g., Dansgaard et al. 1993; Grootes et al. 1993; Broecker 2000, 2006; Rohling et al. 2003; Capron et al. 2010; and references therein). Overall, however, our compilation reveals a coherent global picture, which is particularly clear when plotting the regression slopes from all records as a simple function of latitude (Fig. 6). Here, it is important to emphasize that Fig. 6 simply compares all individual records with equal weighting. Once the geographic SST database grows, it will be important to perform spatial binning of the data and, ideally, data assimilation in models. With the limited geographic coverage available now, however, our first-order approach provides sufficient information to (i) highlight the need for further data generation to enable more sophisticated analysis and (ii) suggest an apparently coherent pattern with latitude, as discussed in the following.

Because all SST records are divided by the same factor $\left(\Delta F_{\text {tot }}\right)$, the $\Omega$ values in Fig. 6a portray the normalized underlying pattern of SST changes on glacial-interglacial time scales. The actual data in Fig. 6a suggest that some sharper gradients exist around the tropics but that the fundamental pattern was almost symmetrical around the equator, as is exemplified by a good quadratic fit $\left(r^{2}=0.6\right.$, $N=36$ ). This fit is determined (solid) using the marine data only and projected (dashed) beyond the latitudinal reach of the marine data toward the poles. The shaded area represents approximate $95 \%$ confidence limits to the fit. Using the stated uncertainty limits, the simple mean global $\Omega$ determined from the quadratic fits through all our compiled marine records is about $0.9(-0.4 /+0.2)^{\circ} \mathrm{C}$ ( $\left.\mathrm{W} \mathrm{m}^{-2}\right)^{-1}$ (Fig. 6b). However, because different latitude bands around the planet comprise different surface areas, an area-weighted mean is more appropriate. We therefore use the quadratic fits for $\Omega$ with latitude to calculate mean $\Omega$ values in $10^{\circ}$ latitude bands and find that the area-weighted mean global $\Omega$ is $0.7(-0.3 /+0.2)^{\circ} \mathrm{C}$ $\left(\mathrm{W} \mathrm{m}^{-2}\right)^{-1}$, where we emphasize that the mean global $\Omega$ concerns sea surface temperature responses only (terrestrial temperature changes may be more variable).

The inferred parabolic pattern around the equator suggests an increase in temperature sensitivity to radiative
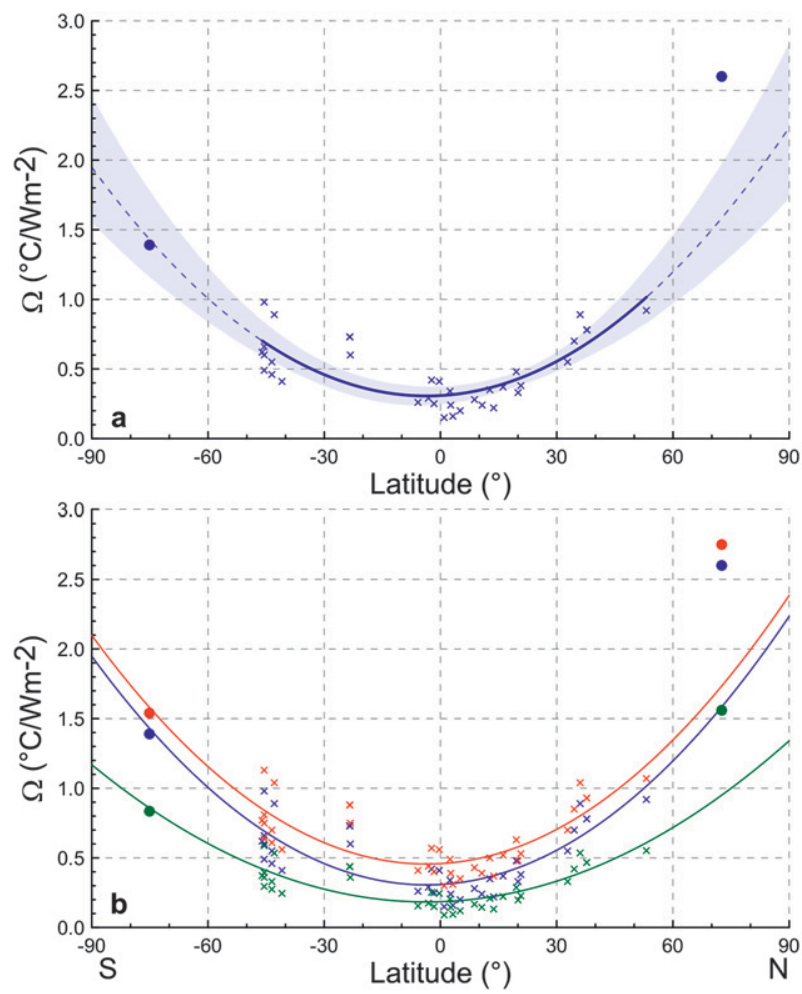

FIG. 6. (a) Regression slopes $\Omega_{\text {regr }}$ (crosses) from Fig. 5 and Table 2 vs latitude. A second-order polynomial fit is presented based on only the marine data (solid) and extrapolated toward the poles (dashed). Shaded interval denotes $95 \%$ confidence interval for the fitted polynomial. Filled dots denote $\Omega_{\text {regr }}$ for Antarctic EPICA Dome C and Greenland GISP2, for comparison with the poleward projections of the polynomial fit. (b) Best estimate range of uncertainties, $\left(0.6 \Omega_{\text {regr }}\right)<\Omega<\left(\Omega_{\text {regr }}+0.2\right)$ as described in section 4 . Because of the largely systematic nature of the uncertainties (proportionally similar for all points), the uncertainties predominantly determine a range within which the entire dataset may be systematically translated up or down. The upper (red) and lower (green) boundaries for the total range of such translations are shown, along with second-order polynomial fits, for comparison with the blue case that replicates (a).

forcing toward the poles, consistent with expectations of polar amplification. However, this is based on the average radiative forcing as if it were homogeneously distributed over the planet, and the high apparent sensitivity per unit forcing at the poles suggested by Fig. 6a may indicate that this assumption is flawed. Below, we evaluate the influence of the spatially inhomogeneous distribution of radiative change.

\section{Inhomogeneous distribution of radiative forcing in $10^{\circ}$ latitude bands and comparison with temperature response records}

None of the radiative forcings considered have evenly distributed impacts around the globe. The pattern of radiative forcing due to $\mathrm{CO}_{2}$ is thought to be virtually 
symmetric between the two hemispheres, with higher forcing over the tropics and a progressive decrease toward high latitudes (Ramanathan et al. 1979; Raval and Ramanathan 1989; Shine and Forster 1999; Broccoli 2000). This distribution is controlled by the temperature dependence of the $15-\mu \mathrm{m}$ Planck function and the opacity of $\mathrm{CO}_{2}$ absorption bands (as temperature decreases so does the Planck function and the opacity of the $\mathrm{CO}_{2}$ absorption bands) with an additional influence from differences in the tropospheric amount of water vapor between high and low latitudes (Ramanathan et al. 1979). We approximate the meridional distribution of the GHG-related forcing based on the $\mathrm{CO}_{2}$ impacts described by Ramanathan et al. We express this with a multiplier $m$, so the contribution of area-weighted "local" greenhouse gas forcing $\Delta F_{\mathrm{GHG} \text { (loc) }}$ (zonally averaged in $10^{\circ}$ latitude bands) to the globalmean greenhouse gas forcing is given as

$$
\Delta F_{\mathrm{GHG}(\mathrm{loc})}=(m / f) \Delta F_{\mathrm{GHG}},
$$

where $f$ is the fraction of the earth's surface area in each $10^{\circ}$ latitude band.

A similar procedure is followed for the variable icesheet albedo component, following the distribution of forcing after Broccoli (2000, his Fig. 1); see also Manabe and Broccoli (1985), Broccoli and Manabe (1987). For the variable dust-forcing component we again repeat the same procedure, using the distribution of dust forcing as described by Claquin et al. (2003). Figure 7a shows the meridional distribution of $\mathrm{m} / \mathrm{f}$ used for the various forcings. For the propagation of uncertainties, we assume that these are proportionally distributed to the forcing impacts. Multiplication of the $m / f$ distribution of Fig. 7a with the globally averaged forcing records (Fig. $3)$ then approximates the zonally averaged components $\Delta F_{\mathrm{GHG}(\mathrm{loc})}, \Delta F_{\mathrm{alb}(\mathrm{loc})}$, and $\Delta F_{\mathrm{du}(\mathrm{loc})}$ for each $10^{\circ}$ latitude band, with their proportional uncertainties.

One further forcing component now needs to be included. When determining zonal mean forcing for $10^{\circ}$ latitude bands, insolation cannot be ignored as was done in the global mean case; its global mean effect may be small, but its regionally specific influences can be considerable. We approximate time series of zonal mean values for insolation at the top of the atmosphere (ToA) for each of the $10^{\circ}$ latitude bands (Laskar et al. 2004) and express these, similar to all other records, as anomalies relative to the AD1000 value. Because annual mean values are used, we do not cover seasonal variability and thus the precessioninduced aspects of insolation forcing. We note that local/ regional surface temperature does not reflect insolation at the ToA but rather the absorbed component of insolation. Therefore, we multiply ToA insolation by $(1-\alpha)$, where $\alpha$ is zonally averaged planetary albedo for each $10^{\circ}$ latitude
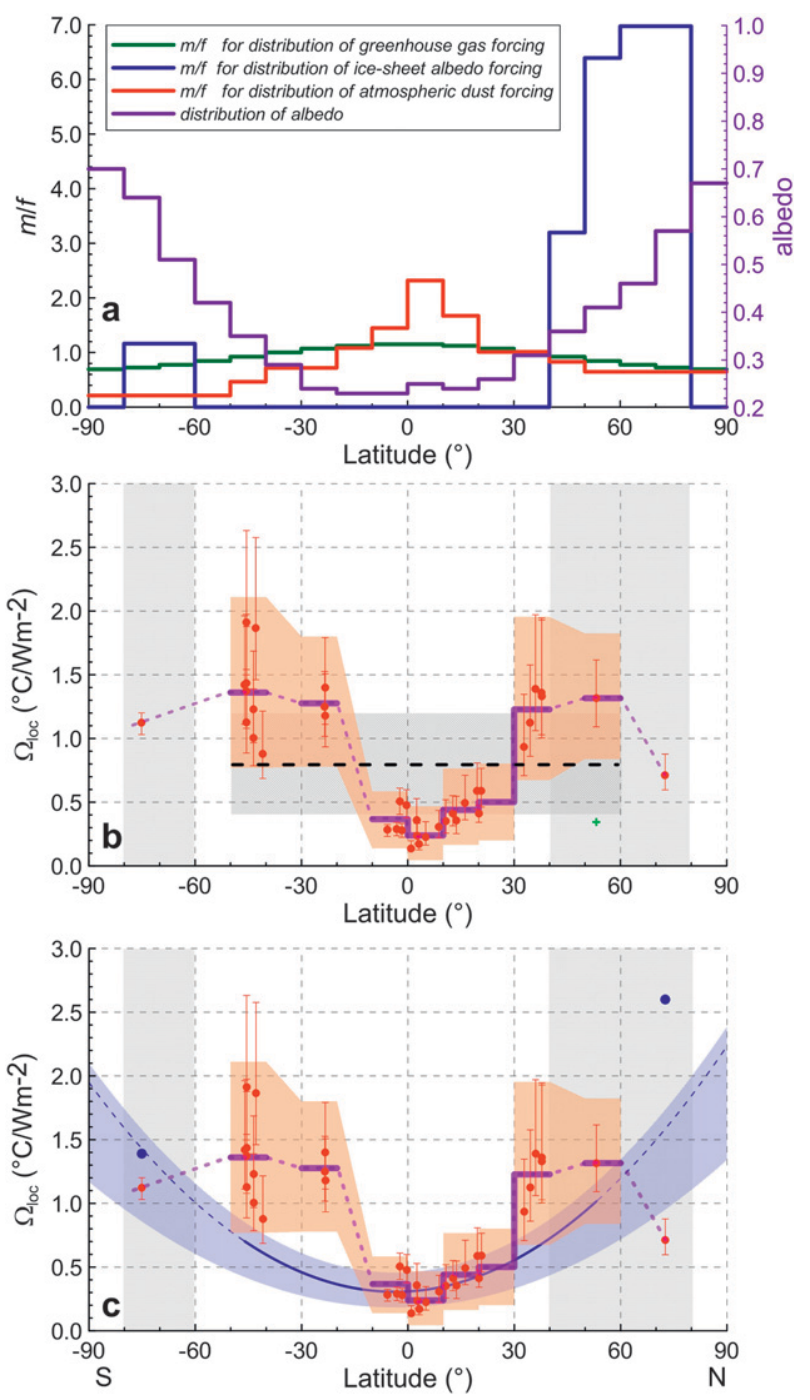

FIG. 7. (a) Area-weighted scale factors used to calculate the zonal mean distribution of the impacts of the main causes of radiative change, after Ramanathan et al. (1979), Broccoli (2000), and Claquin et al. (2003). Also shown is zonal mean distribution of albedo (after Fasullo and Trenberth 2008) used in the calculations of the absorbed component of insolation. (b) Comparison of SST changes relative to zonal mean radiative change in $10^{\circ}$ latitude bands. Red dots are results per discrete record (Fig. 1) with uncertainties. Purple solid lines show means per $10^{\circ}$ latitude band (dashed purple lines are indicative only), and orange band shows total uncertainty interval (see section 5). Dashed black line shows global mean based on area-weighted values in the determined latitude bands, with total uncertainty band (gray). Vertical gray bands highlight latitude bands with large terrestrial (ice sheet volume related) changes in albedo. Green dot indicates the SST response per unit radiative forcing in record 2 when including $\Delta F_{\text {alb(loc) }}$ while the red dot used for that record excludes that influence (see text). (c) As in (b), but comparing the results with the (parabolic) range of solutions of Fig. 6b (blue). 

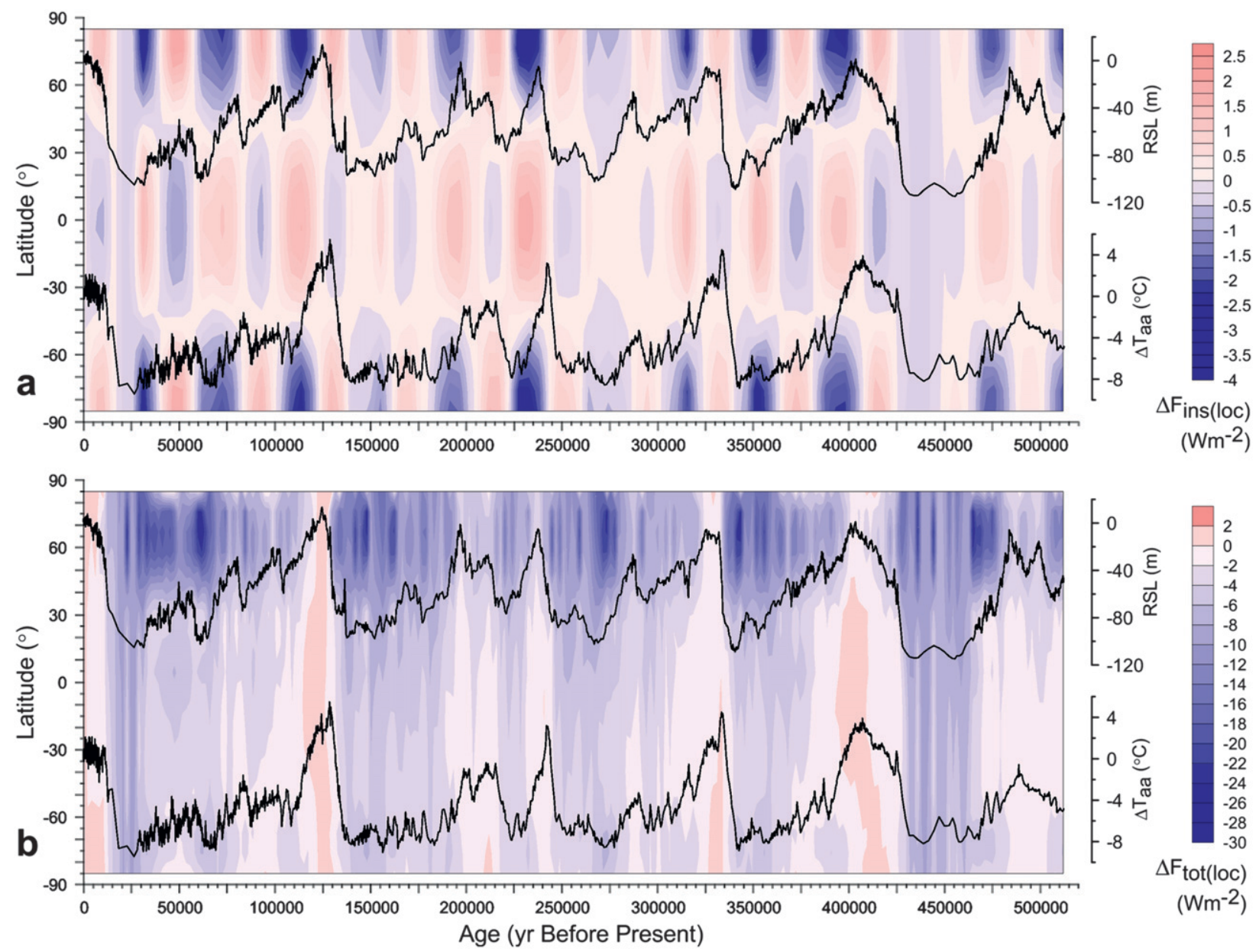

FIG. 8. (a) Orbitally induced changes in (surface-absorbed) insolation relative to AD1000 calculated in zonal means for $10^{\circ}$ latitude bands $\Delta F_{\text {ins(loc) }}$. The overlays show the time series for sea level change (RSL) and Antarctic temperature anomaly $\Delta T_{\text {aa }}$, for comparison of the insolation changes with key environmental changes through the period concerned. Contour gridding based on 5-kyr bands because of the purely orbital nature of these changes. (b) Changes in the total explicit radiative forcing calculated in zonal means for $10^{\circ}$ latitude bands $\Delta F_{\text {tot(loc). }}$ Contour gridding based on 2-kyr bands to emphasis multimillennial and longer variability characterized by the various component time series. Overlays for comparison as in (a).

band, after Fasullo and Trenberth (2008) (Fig. 7a). We do not invoke temporal changes in this albedo term because we explicitly account for albedo changes through time with $\Delta F_{\mathrm{alb}(\mathrm{loc})}$ and $\Delta F_{\mathrm{du}(\mathrm{loc})}$. Hence, it suffices to use the Fasullo and Trenberth albedo values for the present interglacial to determine the baseline albedo modification of insolation. This procedure provides $\Delta F_{\text {ins(loc) }}$ (see Fig. 8a), and the total radiative change per latitude band then is $\Delta F_{\text {tot(loc) }}=$ $\Delta F_{\mathrm{GHG}(\mathrm{loc})}+\Delta F_{\mathrm{alb}(\mathrm{loc})}+\Delta F_{\mathrm{du}(\text { loc })}+\Delta F_{\text {ins(loc) }}$ (see Fig. 8b).

Given that $\Delta F_{\text {ins(loc) }}$ is the only strictly external forcing function, it is useful to reemphasize that, for each major phase of glacial inception/acceleration, ice volume increase (sea level lowering, measured here for the first time with a sea level record that is independent from astronomical tuning) clearly coincided with a maximum contrast between enhanced $\Delta F_{\text {ins(loc) }}$ at low latitudes and reduced $\Delta F_{\text {ins(loc) }}$ at high latitudes (Fig. 8a). This would have optimized vapor transport from low to high latitudes and the preservation of snow/ice at high latitudes, similar to previous suggestions (e.g., Vimeux et al. 1999; Khodri et al. 2001; Raymo and Nisancioglu 2003). The endogenous (slow) feedback processes then sustained and amplified the trend into glacial maxima (Fig. $8 \mathrm{~b}$ ). Figure $8 \mathrm{~b}$ also suggests that the distribution of the radiative forcing maxima that underlie peak interglacial warm conditions may have been somewhat diachronous across latitudes, starting and especially ending first at high latitudes and later at low latitudes. This aspect, which is especially clear in Marine Isotope Stage (MIS) 11, 9, and 5e ( 410, 330, and $\sim 125 \mathrm{ka}$ ), will be important to consider in future studies that may attempt synchronization of temperature records in suborbital detail. This inference, obtained here for the first time from a latitudinal reconstruction of all major radiative forcing components, supports previous 

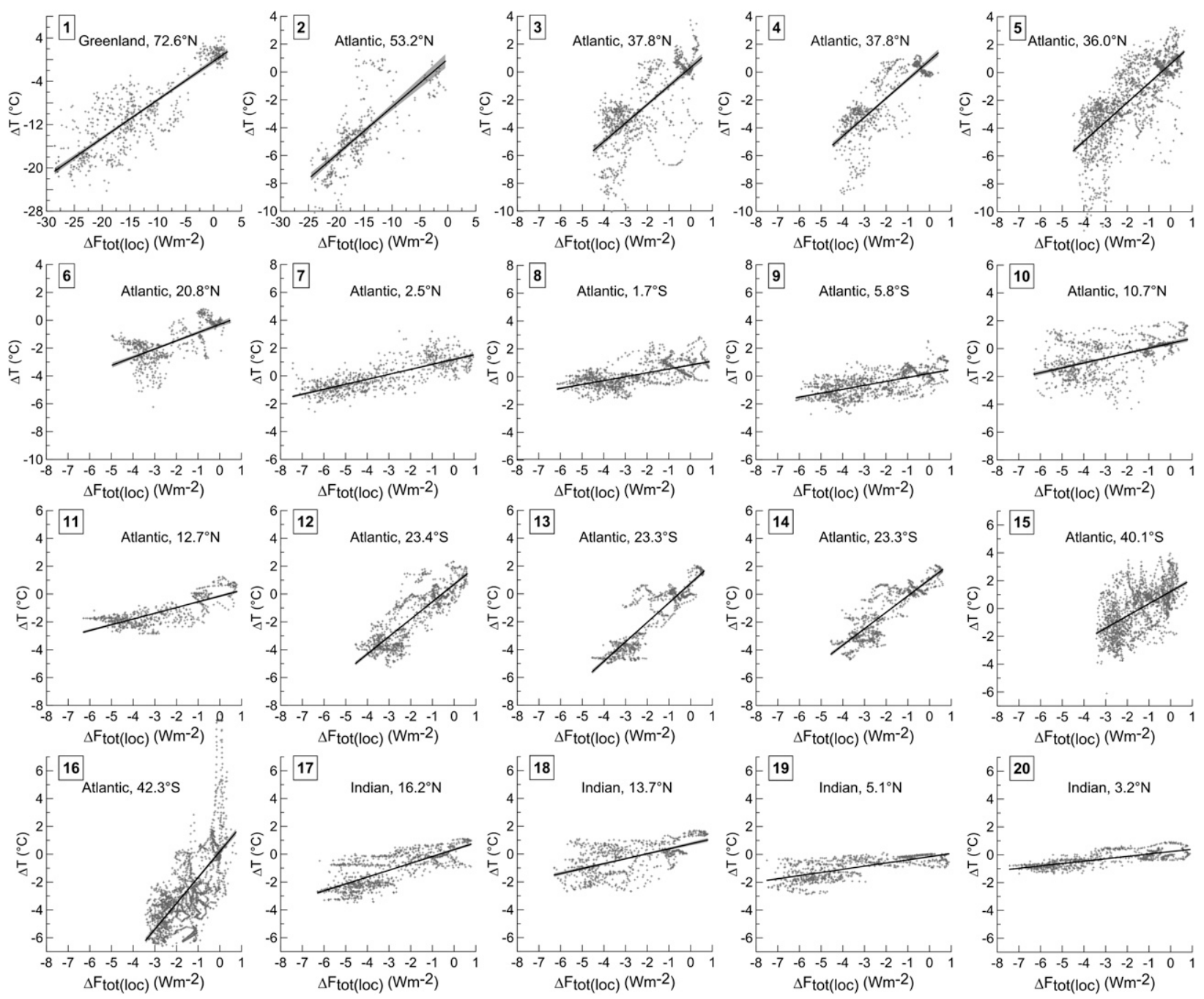

FIG. 9a. (a) Linear regressions between zonal mean radiative forcing as calculated in $10^{\circ}$ latitude bands $\Delta F_{\text {tot(loc) }}$ and relative temperature change for the various locations studied here: numbers 1-20 correspond to descriptions in Tables 1 and 2 . Shading denotes $95 \%$ confidence limits to the fitted linear regressions (i.e., for the fit itself, not for data around the fit).

palaeoclimate reconstructions, which highlight that these expected diachroneities indeed seem to exist, with potential relationships to millennial-scale heat redistributions (e.g., Cortijo et al. 1999; Davis et al. 2003; Brewer et al. 2008; Masson-Delmotte et al. 2010b).

Figure 9 compares the various SST records with the appropriate records of total radiative change per latitude band $\left[\Delta F_{\text {tot(loc) }}=\Delta F_{\mathrm{GHG}(\mathrm{loc})}+\Delta F_{\mathrm{alb}(\mathrm{loc})}+\Delta F_{\mathrm{du}(\mathrm{loc})}+\right.$ $\Delta F_{\text {ins(loc) }}$, and the regression slope values (Table 3) are plotted in Fig. $7 \mathrm{~b}$. One caveat to consider is that $\Delta F_{\mathrm{alb} \text { (loc) }}$ constitutes a terrestrial (ice sheet) impact. Although the large radiative forcing effects due to ice sheet albedo will affect the surrounding oceans, any temporal changes in such influences - distributed by climate dynamics—-would require assessment with coupled climate models that include dynamic ice sheets, which is beyond the scope of this study. Because of this uncertainty, we are cautious about interpreting our SST comparisons with forcing for the latitudes where $\Delta F_{\mathrm{alb} \text { (loc) }}$ becomes dominant (Figs. 7b,c) and do so by considering results that either include or exclude the impact of $\Delta F_{\mathrm{alb}(\mathrm{loc})}$. This affects only one of our SST records (record 2 from $53^{\circ} \mathrm{N}$ ). For terrestrial temperature data, such as that of Greenland, this is of course not an issue; these can be compared in a straightforward manner with the local forcing sums including $\Delta F_{\text {alb(loc). }}$

Where Fig. 6 displays the latitudinal distribution of $\Omega$ as determined by comparison of the local SST responses with the global mean forcing changes $\left(\Omega=\Delta T_{\text {lod }} / \Delta F_{\text {tot }}\right)$, Fig. 7b shows the new values $\Omega_{\text {loc }}$ as determined by comparison of the local SST responses with the zonal mean radiative forcing in the appropriate $10^{\circ}$ latitude band $\left(\Omega_{\mathrm{loc}}=\Delta T_{\mathrm{loc}} / \Delta F_{\text {tot(loc })}\right)$ (see Table 3$)$. After "binning" the 

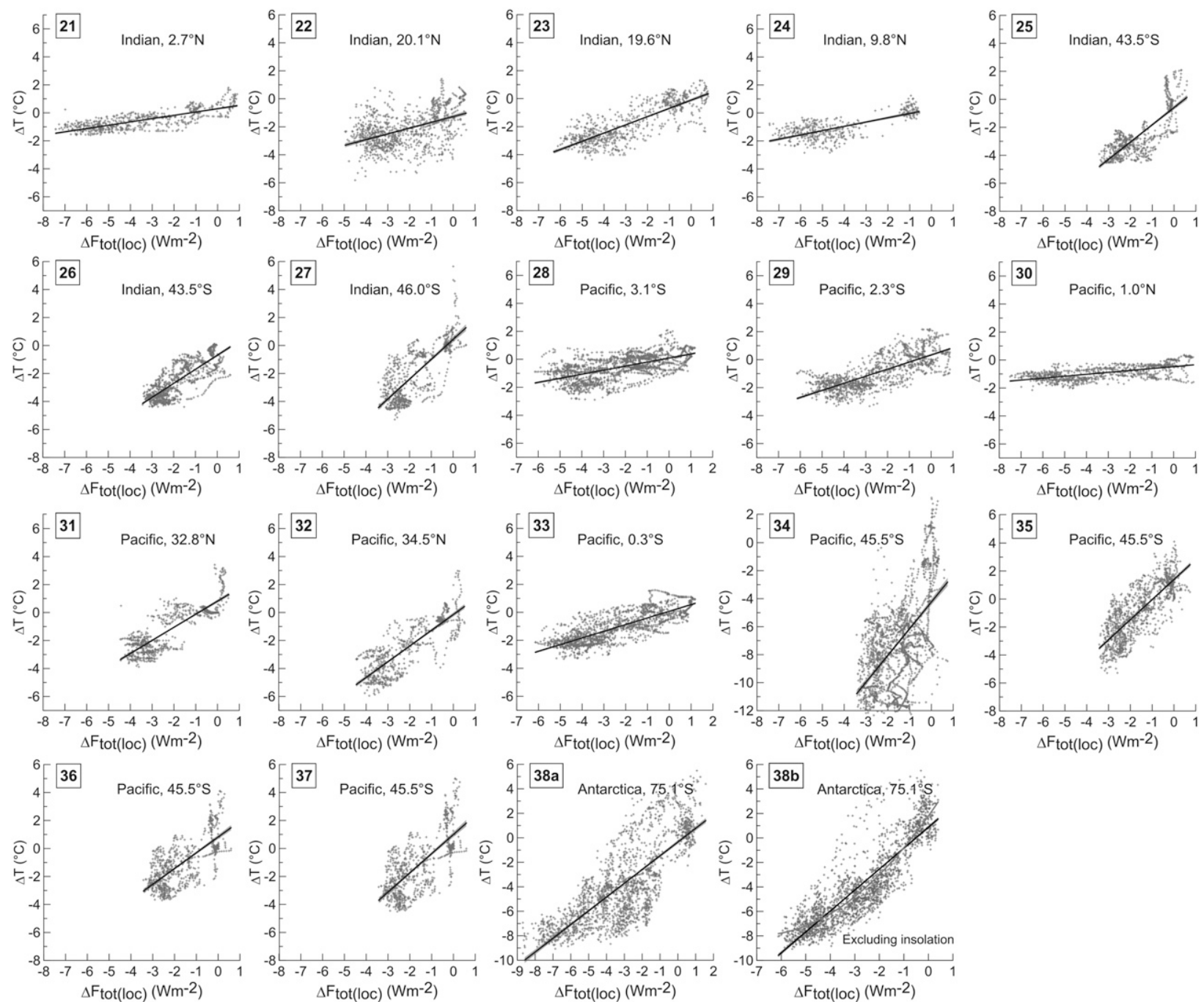

FIG. 9b. As in (a), but for numbers 21-38.

data per latitude band, a global area-weighted mean SST sensitivity is determined in the range of $0.8 \pm 0.4 \mathrm{~W} \mathrm{~m}^{-2}$ (Fig. 7b). Note that the uncertainty band around the mean (gray) is directly related to the uncertainty band to the various $\Omega_{\mathrm{loc}}$ estimates (orange); these uncertainties are not stochastic relative to each other but, instead, reflect the ranges of largely systematic uncertainties.

\section{Implications}

Our global mean SST sensitivity is not the same property as global climate sensitivity. The latter also includes terrestrial temperature responses, which modeling studies estimate to be 1.3 or 1.5 times stronger than marine temperature responses (Braconnot et al. 2007; Laîné et al. 2009). Using our global-mean marine temperature response of $0.8 \pm 0.4 \mathrm{~W} \mathrm{~m}^{-2}$ and adjusting for the stronger terrestrial response, as well as the sea:land area distribution of about 0.7:0.3, we estimate global climate sensitivity at $s=0.85(-0.4 /+0.5)$. This is coherent within the uncertainties with other estimates for global climate sensitivity. Knutti and Hegerl (2008) reviewed climate modeling results to infer that the global climate sensitivity has a range around $0.8(-0.3 /+0.4)^{\circ} \mathrm{C}\left(\mathrm{W} \mathrm{m}^{-2}\right)^{-1}$. OttoBliesner et al. (2009) determined that PMIP2 models with a climate sensitivity of $0.7-0.83^{\circ} \mathrm{C}\left(\mathrm{W} \mathrm{m}^{-2}\right)^{-1}$ best simulated the LGM SSTs reconstructed by the MARGO project members (2009). Köhler et al. (2010) inferred a range around $0.65(-0.3 /+0.8)^{\circ} \mathrm{C}\left(\mathrm{W} \mathrm{m}^{-2}\right)^{-1}$ from a data-led study, which (similar to our estimate) also explicitly accounted for the dust feedback.

If we had not explicitly accounted for the dust feedback, but instead considered it as a fast feedback to be implicitly considered within the climate sensitivity term, then our 
TABLE 3. Regression statistics for the linear regressions shown in Fig. 9; headings as in Table 2. "Slope min" and "Slope max" indicate uncertainties on the slope value. Uncertainties are not stochastic relative to each other but will be systematically low or high for all. Final column shows regression coefficients in a case where insolation is not considered (Ex insol) (see section 6).

\begin{tabular}{|c|c|c|c|c|c|c|c|c|c|c|c|c|}
\hline Number & Slope & $N$ & SSR & SSE & MSR & MSE & $F$ statistic & RMSE & $r^{2}$ & Slope min & Slope max & $r^{2}($ Ex insol $)$ \\
\hline 1 & 0.71 & 633 & 24214.10 & 8179.94 & 24214.10 & 12.96 & 1868 & 3.60 & 0.75 & 0.60 & 0.88 & 0.74 \\
\hline 2 & 0.34 & 404 & 1308.69 & 1059.80 & 1308.69 & 2.64 & 496 & 1.62 & 0.55 & 0.29 & 0.43 & 0.56 \\
\hline 3 & 1.33 & 833 & 3077.21 & 2999.53 & 3077.21 & 3.61 & 853 & 1.90 & 0.51 & 1.00 & 1.93 & 0.51 \\
\hline 4 & 1.36 & 631 & 2038.72 & 1263.55 & 2038.72 & 2.01 & 1015 & 1.42 & 0.62 & 1.03 & 1.95 & 0.65 \\
\hline 5 & 1.39 & 1669 & 6563.22 & 4944.89 & 6563.22 & 2.97 & 2213 & 1.72 & 0.57 & 1.06 & 1.97 & 0.58 \\
\hline 6 & 0.59 & 542 & 383.64 & 564.27 & 383.64 & 1.04 & 367 & 1.02 & 0.40 & 0.46 & 0.77 & 0.50 \\
\hline 7 & 0.36 & 798 & 540.25 & 361.56 & 540.25 & 0.45 & 1189 & 0.67 & 0.60 & 0.26 & 0.53 & 0.61 \\
\hline 8 & 0.28 & 1062 & 273.87 & 469.15 & 273.87 & 0.44 & 619 & 0.67 & 0.37 & 0.22 & 0.33 & 0.46 \\
\hline 9 & 0.28 & 1055 & 280.61 & 466.94 & 280.61 & 0.44 & 633 & 0.67 & 0.38 & 0.23 & 0.33 & 0.53 \\
\hline 10 & 0.35 & 817 & 368.86 & 1017.19 & 368.86 & 1.25 & 296 & 1.12 & 0.27 & 0.26 & 0.52 & 0.22 \\
\hline 11 & 0.41 & 656 & 386.24 & 250.65 & 386.24 & 0.38 & 1008 & 0.62 & 0.61 & 0.31 & 0.55 & 0.67 \\
\hline 12 & 1.25 & 968 & 2591.36 & 1053.90 & 2591.36 & 1.09 & 2375 & 1.04 & 0.71 & 1.02 & 1.53 & 0.74 \\
\hline 13 & 1.40 & 732 & 2576.70 & 729.27 & 2576.70 & 1.00 & 2579 & 1.00 & 0.78 & 1.11 & 1.79 & 0.74 \\
\hline 14 & 1.18 & 766 & 1791.06 & 642.12 & 1791.06 & 0.84 & 2131 & 0.92 & 0.74 & 0.93 & 1.51 & 0.68 \\
\hline 15 & 0.88 & 1665 & 1406.63 & 2951.46 & 1406.63 & 1.77 & 793 & 1.33 & 0.32 & 0.69 & 1.22 & 0.34 \\
\hline 16 & 1.87 & 1988 & 6863.41 & 9153.78 & 6863.41 & 4.61 & 1489 & 2.15 & 0.43 & 1.46 & 2.58 & 0.44 \\
\hline 17 & 0.49 & 1016 & 849.09 & 605.93 & 849.09 & 0.60 & 1421 & 0.77 & 0.58 & 0.36 & 0.71 & 0.46 \\
\hline 18 & 0.36 & 758 & 332.05 & 614.06 & 332.05 & 0.81 & 409 & 0.90 & 0.35 & 0.25 & 0.55 & 0.24 \\
\hline 19 & 0.23 & 838 & 231.83 & 234.94 & 231.83 & 0.28 & 825 & 0.53 & 0.50 & 0.16 & 0.35 & 0.44 \\
\hline 20 & 0.17 & 788 & 123.92 & 90.32 & 123.92 & 0.11 & 1078 & 0.34 & 0.58 & 0.13 & 0.25 & 0.58 \\
\hline 21 & 0.24 & 659 & 179.51 & 113.74 & 179.51 & 0.17 & 1037 & 0.42 & 0.61 & 0.18 & 0.33 & 0.65 \\
\hline 22 & 0.41 & 1009 & 366.10 & 1277.81 & 366.10 & 1.27 & 289 & 1.13 & 0.22 & 0.34 & 0.48 & 0.35 \\
\hline 23 & 0.59 & 731 & 911.10 & 455.23 & 911.10 & 0.62 & 1459 & 0.79 & 0.67 & 0.44 & 0.81 & 0.71 \\
\hline 24 & 0.31 & 426 & 148.83 & 142.55 & 148.83 & 0.34 & 443 & 0.58 & 0.51 & 0.22 & 0.44 & 0.59 \\
\hline 25 & 1.23 & 710 & 1194.34 & 748.90 & 1194.34 & 1.06 & 1129 & 1.03 & 0.61 & 0.97 & 1.69 & 0.63 \\
\hline 26 & 1.01 & 1073 & 1107.96 & 612.44 & 1107.96 & 0.57 & 1938 & 0.76 & 0.64 & 0.79 & 1.39 & 0.64 \\
\hline 27 & 1.42 & 710 & 1498.31 & 1124.25 & 1498.31 & 1.59 & 944 & 1.26 & 0.57 & 1.11 & 1.96 & 0.58 \\
\hline 28 & 0.29 & 1966 & 499.84 & 898.25 & 499.84 & 0.46 & 1093 & 0.68 & 0.36 & 0.24 & 0.34 & 0.47 \\
\hline 29 & 0.51 & 1292 & 1027.44 & 751.70 & 1027.44 & 0.58 & 1763 & 0.76 & 0.58 & 0.40 & 0.61 & 0.72 \\
\hline 30 & 0.14 & 1013 & 99.83 & 155.13 & 99.83 & 0.15 & 651 & 0.39 & 0.39 & 0.12 & 0.20 & 0.42 \\
\hline 31 & 0.94 & 797 & 1431.20 & 593.62 & 1431.20 & 0.75 & 1917 & 0.86 & 0.71 & 0.71 & 1.35 & 0.72 \\
\hline 32 & 1.12 & 687 & 1653.53 & 739.64 & 1653.53 & 1.08 & 1531 & 1.04 & 0.69 & 0.86 & 1.58 & 0.74 \\
\hline 33 & 0.48 & 1673 & 1299.30 & 731.11 & 1299.30 & 0.44 & 2970 & 0.66 & 0.64 & 0.38 & 0.60 & 0.71 \\
\hline 34 & 1.91 & 1972 & 6646.43 & 13283.90 & 6646.43 & 6.74 & 986 & 2.60 & 0.33 & 1.50 & 2.63 & 0.33 \\
\hline 35 & 1.44 & 1222 & 2711.85 & 1582.33 & 2711.85 & 1.30 & 2091 & 1.14 & 0.63 & 1.13 & 1.98 & 0.63 \\
\hline 36 & 1.13 & 788 & 1183.36 & 1102.39 & 1183.36 & 1.40 & 844 & 1.18 & 0.52 & 0.89 & 1.54 & 0.51 \\
\hline 37 & 1.37 & 788 & 1754.45 & 1634.48 & 1754.45 & 2.08 & 844 & 1.44 & 0.52 & 1.08 & 1.88 & 0.51 \\
\hline 38 & 1.12 & 2052 & 13159.70 & 8406.51 & 13159.70 & 4.10 & 3209 & 2.03 & 0.61 & 1.03 & 1.20 & 0.76 \\
\hline
\end{tabular}

global mean SST sensitivity estimate would increase to $0.95^{\circ} \mathrm{C}\left(\mathrm{W} \mathrm{m}^{-2}\right)^{-1}$ and our associated estimate of global climate sensitivity to about $s=1.05^{\circ} \mathrm{C}\left(\mathrm{W} \mathrm{m}^{-2}\right)^{-1}$. Uncertainties are similar to those given above. Note that the values that apply to the fast anthopogenic forcing of climate may differ from our reconstructions of long-term (quasi-equilibrium) natural change.

The meridional distribution of SST sensitivity to regional radiative forcing (Figs. 7b,c) reveals a pattern with sharp steps that clearly exceed uncertainties. Values are low at the tropics and elevated at midlatitudes. Our first scenario shows that these steps, in part, derive from the actual SST distribution, that is, low tropical SST values and higher subtropical SST values (Fig. 6a). It is noteworthy that the transitions coincide in latitudinal position with that between tropical regions with very little seasonal SST contrast and midlatitude regions with amplified seasonal SST contrasts (e.g., Fig. 6.3 of Stewart 2008). The amplified SST sensitivity in the subtropical to midlatitude regions (Figs. 7b,c) may therefore (in part) reflect amplified cooling during glacials in subtropical/midlatitude regions with a distinct seasonal bias, for example, due to intensified winter cooling downwind of cold glacial continents.

The amplification of the SST response steps around $20^{\circ}-30^{\circ}$ latitude in the second scenario (Figs. $7 \mathrm{~b}, \mathrm{c}$ ), where comparison is made with more regionally specific forcing, derives from an increase in the effects due to the inhomogeneous latitudinal distribution of radiative forcing - that is, larger tropical forcing changes and smaller subtropical forcing changes. This highlights an important 
issue regarding our understanding of the tropical and subtropical temperature sensitivities per unit forcing. In both of our scenarios, tropical temperature sensitivity remains considerably below the global-mean temperature sensitivity ( $\left.\varphi=\Omega_{\text {loc }} / \Omega_{\text {global }}<1\right)$-that is, something causes "tropical dampening" (Figs. 6 and 7b). Especially in the second scenario, subtropical sensitivity appears to be above the global mean $(\varphi>1$, subtropical amplification) (Fig. 7b). Given that the latitudinal positions of the step changes coincide with the edges of the zone of tropical hydrological fluctuations and the equatorward limit of the oceanic subtropical gyres, (parts of) these sharp steps may arise from processes associated with the tropical hydrological cycle (e.g., cloud feedback) with efficient heat advection away from the tropics and/or with large-scale mixing in the subtropical gyres.

Going from the midlatitudes toward the high-latitude polar ice-core records, Figs. 7b,c suggest some decrease in temperature sensitivity to central estimates of $\varphi=1.4$ (Antarctica) and $\varphi=0.9$ (Greenland), within ranges of 1.0-2.5 and 0.7-1.5, respectively. We discuss first the Antarctic case, and then the Greenland case, but first emphasize that the term "polar amplification" is used here within a context of sensitivity to unit local forcing, rather than simply as polar temperature change relative to global temperature change. In our approach, a sound accounting for the main radiative changes in the polar latitudes should negate polar amplification or-conversely-the presence of an apparent polar amplification value would imply that an important local forcing factor may have been overlooked or underestimated. We also emphasize that our values depend on the reported amplitudes of the Greenland and Antarctic temperature records. Borehole temperature profiles and new temperature calibration methods for the ice cores suggest that the glacial-interglacial amplitudes may be larger (e.g., DahlJensen et al. 1998; Vinther et al. 2009b; Stenni et al. 2010; Capron et al. 2010), in which case our polar amplification factors would be underestimates. However, none of the resultant adjusted, continuous, temperature time series were available (yet) on public data servers.

In our initial comparison between the Antarctic EDC temperature record $\Delta T_{\mathrm{aa}}$ and the mean global forcing changes $\Delta F_{\text {tot }}$, the linear regression does not describe the data distribution very well (number 38 in Fig. 5b). Instead, partial linear regressions throughout the dataset over successive intervals of $2 \mathrm{~W} \mathrm{~m}^{-2}$ suggest steepening of the slope by a factor of $\sim 3$ from 0.8 to $2.4^{\circ} \mathrm{C}\left(\mathrm{W} \mathrm{m}^{-2}\right)^{-1}$ with increasing values of $\Delta F_{\text {tot }}$, which can be reasonably represented by a quadratic fit (Fig. 5b) that would suggest that Antarctic climate becomes increasingly sensitive under increasingly warm conditions [see very similar evaluation in Masson-Delmotte et al. (2010a)]. However, when comparing $\Delta T_{\text {aa }}$ with $\Delta F_{\text {tot(loc) }}$ for the appropriate latitude band, there is no longer a firm statistical basis for using a curvilinear fit (38a in Fig. 9b). Note that the deterioration between the regression of $\Delta T_{\mathrm{aa}}$ versus $\Delta F_{\text {tot(loc) }}$ (38a in Fig. 9b) relative to the regression versus $\Delta F_{\text {tot }}$ (38 in Fig. 5b) may be because $\Delta F_{\text {tot(loc) }}$ includes insolation, given that we do not consider the potential for (long) lags between insolation and temperature response (e.g., through ice sheet altitude changes), as previously discussed in MassonDelmotte et al. (2010a). To test this, panel 38b of Fig. 9b shows a regression of $\Delta T_{\text {aa }}$ against $\Delta F_{\text {tot(loc) }}$ excluding insolation, in which case the nonlinear response becomes obvious again. Our SST regressions versus $\Delta F_{\text {tot(loc) }}$ mostly are less sensitive to the inclusion or exclusion of insolation, but some correlation coefficients do change (Table 3, right-hand column). This highlights that SST at each site is not a pure reflection of the latitude-specific radiation balance, but that there are important additional influences (e.g., large-scale advection), which confirms that the two scenarios elaborated in this paper are end-member views as outlined in section 1 .

The linear regressions of $\Delta T_{\text {aa }}$ versus $\Delta F_{\text {tot(loc) }}$ in panels 38a and 38b (Fig. 9b) have similar slopes, which suggest that the Antarctic temperature sensitivity was around $1.1 \pm 0.1^{\circ} \mathrm{C}\left(\mathrm{W} \mathrm{m}^{-2}\right)^{-1}$, compared to an area-weighted mean global SST sensitivity of $0.8 \pm 0.4^{\circ} \mathrm{C}\left(\mathrm{W} \mathrm{m}^{-2}\right)^{-1}$ (where the uncertainties are systematically related between both values). This gives the normalized amplification factor $\varphi=1.4$ within a total range of 1.0-2.5. This entirely data-dependent estimate compares well with the modeling-based range of 1.2-2.1 for Antarctic polar amplification by Masson-Delmotte et al. (2006, 2010a). The stated range is the linear mean value over several glacial cycles, but similar to Masson-Delmotte et al. (2010a), we find that the relationship in more detail appears to be distinctly curvilinear, with lower Antarctic temperature sensitivity during glacial times and higher sensitivity during warmer climate states.

We suggest that the inferred mean amplification effect may have resulted from sea ice albedo feedbacks around the Antarctic continent that our analysis has not accounted for, due to the enormous changes in circum-Antarctic sea ice area between interglacials and glacials (annual mean change from $8.5 \times 10^{12} \mathrm{~m}^{2}$ today to $22 \times 10^{12} \mathrm{~m}^{2}$ during the LGM, as summarized by Köhler et al. 2010). A simple scale analysis is possible. An amplification factor of 1.4 would imply that we underestimated the radiative change by about $0.4 \Delta F_{\operatorname{tot}\left(70^{\circ}-80^{\circ} \mathrm{S}\right)} \mathrm{W} \mathrm{m}^{-2}$, which amounts to a cycle with an amplitude of about $3.5 \mathrm{~W} \mathrm{~m}^{-2}$. If due to sea ice, then this radiative effect would have been applied over the larger surface area of the $60^{\circ}-70^{\circ} \mathrm{S}$ latitude band directly around Antarctica and correction for the ratio of areas gives a cycle with a glacial-interglacial 
amplitude on the order of $0.6 \times 3.5=2 \mathrm{~W} \mathrm{~m}^{-2}$. This simple scale analysis is in good agreement with the $1.7 \mathrm{~W} \mathrm{~m}^{-2}$ calculated by Köhler et al. (2010) for the radiative impact of sea ice albedo in the Southern Hemisphere. This supports our concept that the factor $\varphi=1.4$ for the Antarctic temperature response results from the fact that we did not explicitly account for changes in the radiative balance at the high southern latitudes owing to the long-term sustained changes in sea ice coverage. The apparent curvilinear relationship (panel 38 in Fig. 5b and panel 38b in Fig. 9b) requires further study.

In contrast to the case for Antarctica, we find that the Greenland temperature sensitivity to radiative forcing was close to the global mean (i.e., $\varphi \approx 1$ ) (Fig. 7b); the large temperature fluctuations in Greenland simply reflect similarly large local forcing variations at high northern latitudes (Figs. 7 and 9). This provides context to studies of Arctic polar amplification. If long-term Arctic polar amplification is considered as the simple ratio $\Delta T_{\text {arctid }} \Delta T_{\text {global }}$ without accounting for the inhomogeneous distribution of climate forcing on especially the Northern Hemisphere (e.g., Miller et al. 2010), then it seems high only because $\Delta F_{\text {arctic }} / \Delta F_{\text {global }}$ was large because of the strong dominance of ice sheet albedo changes. To avoid this bias, it is better to consider polar amplification in terms of temperature sensitivity normalized to unit local forcing $\left[{ }^{\circ} \mathrm{C}\left(\mathrm{W} \mathrm{m}^{-2}\right)^{-1}\right]$. Doing so, we find $\varphi \approx 1$ for Greenland, which suggests that no major radiative changes have been overlooked. Assuming that it is representative for the wider Arctic region, this would imply that long-term sea ice changes apparently were too small to have caused substantial radiative changes in the Northern Hemisphere, contrary to the situation in the Southern Hemisphere. This agrees with the fact that most $(75 \%)$ of the glacial-interglacial waxing and waning of sea ice took place around Antarctica [Köhler et al. 2010; for example, see reconstructions of austral sea ice cover in Gersonde et al. (2005)]. Note that this is a long-term perspective in which any sea ice influences on the Northern Hemisphere are "swamped" by the vast ice-sheet albedo influences. The long-term mean sensitivity likely differs from the sensitivity on shorter time scales of a few centuries or less, when Arctic amplification may appear high because of (fast) reductions in the Arctic sea ice cover in the absence of substantial change in ice sheet albedo.

The results allow for some careful speculation about implications for the future. Given the absence of large ice sheets on the Northern Hemisphere today (except for Greenland), there is no scope for similarly large ice sheet albedo changes in the future. After the Arctic sea ice cover and the more climate-sensitive parts of the Greenland ice sheet have disappeared [the modern local radiative forcing increase from Arctic sea ice reduction is on the order of $2-4 \mathrm{~W} \mathrm{~m}^{-2}$ decade $^{-1}$, Kato et al. (2006)], therefore, long-term future radiative forcing changes will be less amplified in the Arctic region relative to the global mean than during glacial-interglacial cycles so that temperature changes will also be less amplified relative to the global mean. In other words, the (middle to) high northern latitude temperatures were "hypersensitive" during glacial-interglacial cycles due to the large ice sheet impacts and thus do not provide a good basis for extrapolation into a mostly ice-free future on the Northern Hemisphere.

In the Southern Hemisphere, the opposite is true. There, continental glaciation has remained almost complete throughout the glacial-interglacial cycles, including the present day. This strongly limited the radiative impacts of ice sheet albedo and thus the temperature changes. Once reductions occur in the scale of continental glaciation over Antarctica, and/or in the sea ice extent around it (in summer still $\sim 4 \times 10^{12} \mathrm{~m}^{2}$ and in winter $\sim 19 \times 10^{12} \mathrm{~m}^{2}$ ), then a strong feedback response may drive further/enhanced warming with a potential for rapid, nonlinear adjustments, similar to those found during deglaciations in the Northern Hemisphere.

\section{Conclusions}

We compile a global suite of marine and ice-core temperature reconstructions for comparison with new reconstructions of the main changes in the radiative balance of climate. Our first scenario uses global-mean radiative forcing changes, and our second scenario uses zonal mean reconstructions of radiative forcing in $10^{\circ}$ latitude bands.

Comparison of the compiled temperature records with the reconstruction of global-mean radiative forcing (first scenario) suggests an area-weighted mean global sea surface temperature (SST) sensitivity of $0.7(-0.3 /+0.2)^{\circ} \mathrm{C}$ $\left(\mathrm{W} \mathrm{m}^{-2}\right)^{-1}$ with a smoothly increasing trend from low values around the equator to high values at high latitudes. Comparison of the temperature records with more regionally specific forcing records in $10^{\circ}$ latitude bands (second scenario) reveals a similar area-weighted global mean sea surface temperature (SST) sensitivity value of $0.8 \pm 0.4^{\circ} \mathrm{C}\left(\mathrm{W} \mathrm{m}^{-2}\right)^{-1}$ but with a significantly different meridional pattern. This pattern shows low values at the low latitudes with a sharp step that clearly exceeds uncertainty to high values at the midlatitudes. Toward higher latitudes, the sensitivity then seems to drop a little, but this remains within uncertainty. We tentatively ascribe the sharp step between the inferred low and middle latitude sensitivities to an unaccounted-for modification of the spatial forcing distribution relative to our reconstructions, possibly related to the tropical-subtropical hydrological cycle/cloud cover. 
Our estimated SST sensitivity is not the same property as global climate sensitivity. Correction for 1.3-1.5 times stronger temperature changes over land suggests an inferred global temperature sensitivity range of 0.85 $(-0.4 /+0.5)^{\circ} \mathrm{C}\left(\mathrm{W} \mathrm{m}^{-2}\right)^{-1}$, which compares well with previously published estimates of global climate sensitivity of $0.8(-0.3 /+0.4)^{\circ} \mathrm{C}\left(\mathrm{W} \mathrm{m}^{-2}\right)^{-1}$ or $0.65(-0.3 /$ $+0.8)^{\circ} \mathrm{C}\left(\mathrm{W} \mathrm{m}^{-2}\right)^{-1}$. Our study thus provides a long time-span perspective to those values, along with a first quantification of the time-variable spatially inhomogeneous distribution of the sensitivity.

We have explicitly accounted for the dust feedback, effectively treating it as a slow feedback term, which might be debated. If we had instead considered it as a fast feedback, then our SST sensitivity estimate would change to about $0.95^{\circ} \mathrm{C}\left(\mathrm{W} \mathrm{m}^{-2}\right)^{-1}$, the associated estimate of global climate sensitivity to about $1.05^{\circ} \mathrm{C}\left(\mathrm{W} \mathrm{m}^{-2}\right)^{-1}$, with uncertainties similar to those given above.

We find that long-term polar amplification, which we measure relative to the global mean and normalized to unit forcing $\left[{ }^{\circ} \mathrm{C}\left(\mathrm{W} \mathrm{m}^{-2}\right)^{-1}\right]$ may be negligible for Greenland (0.9, within a total range of 0.7-1.5), although larger amplification may apply to the Arctic on shorter time scales owing to the fast sea ice albedo processes. If validated, this would imply that Arctic amplification would sharply drop once the Arctic (summer) sea ice cover has been eliminated. Conversely, we observe a persistent long-term mean polar amplification value for Antarctica of 1.4 within a total range of 1.0-2.5. These values strongly support previous independent reconstructions of long-term Antarctic polar amplification, and we suggest that this amplification is due to the very large glacial-interglacial changes in sea ice cover around Antarctica.

Acknowledgments. This study contributes to UK Natural Environment Research Council (NERC) projects NE/C003152/1, NE/I009906/1, and NE/H004424/1. EJR acknowledges support from a Royal Society Wolfson Research Merit Award, and MS acknowledges an RCUK fellowship from the University of Bristol. We thank Andy Jarvis for helpful discussions and assistance with MAGICC, Jim Hansen for discussions about aerosol feedback processes, Peter Köhler for useful feedback, and Valerie Masson-Demotte and two anonymous reviewers for comments and suggestions. Data were obtained from the World Data Center for Marine Environmental Science (WDC-MARE; http://www.wdc-mare.org/), the NOAA National Climatic Data Centre (http://www.ncdc.noaa. gov/paleo/ftp-search.html), and-concerning the new sea level record-from http://www.soes.soton.ac.uk/staff/ ejr/ejrhome.htm. Data files from this study can also be obtained from the latter site.

\section{APPENDIX A}

\section{Radiative Forcing Calculations}

For carbon dioxide, we use

$$
\Delta F_{\mathrm{CO} 2}=5.35 \ln \left(\left[\mathrm{CO}_{2}\right] /\left[\mathrm{CO}_{2}\right]_{\mathrm{ref}}\right) .
$$

For methane, we use

$$
\begin{aligned}
\Delta F_{\mathrm{CH} 4}= & 0.0406\left(\sqrt{ }\left[\mathrm{CH}_{4}\right]-\sqrt{ }\left[\mathrm{CH}_{4}\right]_{\mathrm{ref}}\right) \\
& -\left[0.47 \ln \left\{1+2.01 \times 10^{-5}\left(\left[\mathrm{CH}_{4}\right]\left[\mathrm{N}_{2} \mathrm{O}\right]_{\mathrm{ref}}\right)^{0.75}+5.31 \times 10^{-15}\left[\mathrm{CH}_{4}\right]\left(\left[\mathrm{CH}_{4}\right]\left[\mathrm{N}_{2} \mathrm{O}\right]_{\mathrm{ref}}\right)^{1.52}\right\}\right] \\
& -\left[0.47 \ln \left\{1+2.01 \times 10^{-5}\left(\left[\mathrm{CH}_{4}\right]_{\mathrm{ref}}\left[\mathrm{N}_{2} \mathrm{O}\right]_{\mathrm{ref}}\right)^{0.75}+5.31 \times 10^{-15}\left[\mathrm{CH}_{4}\right]_{\mathrm{ref}}\left(\left[\mathrm{CH}_{4}\right]_{\mathrm{ref}}\left[\mathrm{N}_{2} \mathrm{O}\right]_{\mathrm{ref}}\right)^{1.52}\right\}\right] .
\end{aligned}
$$

In these equations, we use AD1000 values of $\left[\mathrm{CO}_{2}\right]_{\mathrm{ref}}=$ $279 \mathrm{ppmv},\left[\mathrm{CH}_{4}\right]_{\mathrm{ref}}=633 \mathrm{ppb}$, and $\left[\mathrm{N}_{2} \mathrm{O}\right]_{\mathrm{ref}}=270 \mathrm{ppb}$.

The total radiative forcing from $\mathrm{GHG}$ concentration changes $\Delta F_{\mathrm{GHG}}$ (Fig. 2) is determined (Hansen et al. 2008) using

$$
\Delta F_{\mathrm{GHG}}=1.12\left(\Delta F_{\mathrm{CO} 2}+1.4 \Delta F_{\mathrm{CH} 4}\right) .
$$

This includes a scaling factor to account for the impacts of $\mathrm{N}_{2} \mathrm{O}$, which is correlated with $\mathrm{CO}_{2}$ and $\mathrm{CH}_{4}$ (Hansen et al. 2008). This approach is needed because no continuous records exist for $\mathrm{N}_{2} \mathrm{O}$, but it is consistent through intervals where data do exist (Köhler et al. 2010).
Regarding the ice-sheet albedo impact $\Delta F_{\text {alb }}$, Hansen et al. (2008) established that it can be approximated using a linear relationship (appendix B) with a slope of $0.0308 \mathrm{~W} \mathrm{~m}^{-2}$ per meter of sea level change (N.B. decimal point accuracy maintained to that given by Hansen et al. 2008):

$$
\Delta F_{\mathrm{alb}}=0.0308 \Delta \mathrm{SL},
$$

which is referenced to the AD1000 value and where $\Delta$ SL is negative during glacials. We also explored (see Fig. 3) a case where $\Delta F_{\text {alb }}$ is related to ice volume in a nonlinear 
manner (Hansen et al. 2008), using that study's Northern Hemisphere component of the equation: $\Delta F_{\mathrm{alb}}=$ $3.5(\Delta \mathrm{SL} /-105)^{0.8}$.

\section{APPENDIX B}

\section{Correction for the Influence on Our Regression Slopes due to the Impact of the Atmospheric Lapse Rate $\gamma$ on SST during Times with Lowered Sea Level}

Mélières et al. (1991) determined that atmospheric pressure at sea level increases by $9-15 \mathrm{hPa}$ for a sea level drop on the order of $100 \mathrm{~m}$ and that a temperature increase at sea level must be considered. From modern data, Mokhov and Akperov (2006) have determined that the lapse rate over the ocean at the locations of our SST records is between about $0.57^{\circ}$ and $0.63^{\circ} \mathrm{C}(100 \mathrm{~m})^{-1}$ and that the lapse rate over the ocean depends on surface temperature with $d \gamma / d \mathrm{SST}$ within a range of $\pm 0.05^{\circ} \mathrm{C}$ $(100 \mathrm{~m})^{-1}$. Reconstructions for the LGM in Halmahera, Indonesia (Barmawidjaja et al. 1993), and for the central Mediterranean (Kuhlemann et al. 2008) suggest that the lapse rate over colder glacial ocean surfaces may have been considerably steeper than today, which conflicts with the zero to positive $d \gamma / d$ SST over ocean surface at those latitudes in modern seasonal data (Mokhov and Akperov 2006). Clearly, proper inclusion of $d \gamma / d$ SST will require the use of a high-resolution fully coupled oceanatmosphere general circulation model: because the range of glacial-interglacial changes in our SST records is mostly within $5^{\circ} \mathrm{C}$, we ignore $\mathrm{d} \gamma / d \mathrm{SST}$. Hence, we consider the influence of sea level lowering on SST using a modern lapse rate over the ocean surfaces of $0.6^{\circ} \mathrm{C}$ $(100 \mathrm{~m})^{-1}$ (Mokhov and Akperov 2006). At the full glacial sea level lowering (negative extreme of $\Delta F_{\text {tot }}$ ), this would cause a warming at the sea surface of about $0.7^{\circ} \mathrm{C}$.

\section{REFERENCES}

Adkins, J., P. deMenocal, and G. Eshon, 2006: The "African humid period" and the record of marine upwelling from excess $230 \mathrm{Th}$ in Ocean Drilling Program Hole 658C. Paleoceanography, 21, A4203, doi:10.1029/2005PA001200.

Alley, R. B., 2000: The Younger Dryas cold interval as viewed from central Greenland. Quat. Sci. Rev., 19, 213-226.

Andersen, M., and Coauthors, 2010: The timing of sea-level highstands during Marine Isotope Stages 7.5 and 9: Constraints from the uranium-series dating of fossil corals from Henderson Island. Geochim. Cosmochim. Acta, 74, 3598-3620.

Bard, E., 2002: Climate shock: Abrupt climate changes over millennial time scales. Phys. Today, 55, 32-38.

— , F. Rostek, and C. Sonzogni, 1997: Interhemispheric synchrony of the last deglaciation inferred from alkenone palaeothermometry. Nature, 385, 707-710.

— G. Menot-Combes, and F. Rostek, 2004: Present status of radiocarbon calibration and comparison records based on polynesian corals and Iberian Margin sediments. Radiocarbon, 46, 1189-1203.

Barmawidjaja, B. M., E. J. Rohling, W. A. van der Kaars, C. Vergnaud-Grazzini, and W. J. Zachariasse, 1993: Glacial conditions in the northern Molucca Sea region (Indonesia). Palaeogeogr. Palaeoclimatol. Palaeoecol., 101, 147-167.

Becquey, S., and R. Gersonde, 2003: A 0.55-Ma paleotemperature record from the Subantarctic zone: Implications for Antarctic Circumpolar Current development. Paleoceanography, 18, PA1014, doi:10.1029/2000PA000576.

Bintanja, R., R. S. W. van de Wal, and J. Oerlemans, 2005: Modelled atmospheric temperatures and global sea levels over the past million years. Nature, $\mathbf{3 7 5}, 125-128$.

Biton, E., H. Gildor, and W. R. Peltier, 2008: Red Sea during the Last Glacial Maximum: Implications for sea level reconstruction. Paleoceanography, 23, PA1214, doi:10.1029/ 2007PA001431.

Braconnot, P., and Coauthors, 2007: Results of PMIP2 coupled simulations of the mid-Holocene and Last Glacial Maximum - Part 1: Experiments and large-scale features. Climate Past, 3, 261-277.

Brewer, S., J. Guiot, M. F. Sanchez-Goni, and S. Klotz, 2008: The climate in Europe during the Eemian: A multi-method approach using pollen data. Quat. Sci. Rev., 27, 2303-2315.

Broccoli, A. J., 2000: Tropical cooling at the Last Glacial Maximum: An atmosphere-mixed layer ocean model simulation. J. Climate, 13, 951-976.

— mospheric $\mathrm{CO}_{2}$, and land albedo on the climate of the last glacial maximum. Climate Dyn., 1, 87-99.

Broecker, W. S., 2000: Abrupt climate change: Causal constraints provided by the paleoclimate record. Earth Sci. Rev., 51, 137-154. , 2006: Abrupt climate change revisited. Global Planet. Change, 54, 211-215.

Budziak, D., 2001: Late Quaternary Monsoonal Climate and Related Variations in Paleoproductivity and Alkenone-Derived Sea-Surface Temperatures in the Western Arabian Sea. Vol. 170, Berichte, Fachbereich Geowissenschaften, Universitaet Bremen, 114 pp.

Capron, E., and Coauthors, 2010: Millennial and sub-millennial scale climatic variations recorded in polar ice cores over the last glacial period. Climate Past, 6, 345-365.

Charney, J., 1979: Carbon Dioxide and Climate: A Scientific Assessment. National Academy of Sciences Press, 24 pp.

Claquin, T., and Coauthors, 2003: Radiative forcing of climate by ice-age atmospheric dust. Climate Dyn., 20, 193-202.

Collins, W. D., and Coauthors, 2006: Radiative forcing by well-mixed greenhouse gases: Estimates from climate models in the IPCC AR4.J. Geophys. Res., 111, D14317, doi:10.1029/2005JD006713.

Cortese, G., A. Abelmann, and R. Gersonde, 2007: The last five glacial-interglacial transitions: A high-resolution 450 000-year record from the subantarctic Atlantic. Paleoceanography, 22, PA4203, doi:10.1029/2007PA001457.

Cortijo, E., and Coauthors, 1999: Changes in meridional temperature and salinity gradients in the North Atlantic Ocean $\left(30^{\circ}-70^{\circ} \mathrm{N}\right)$ during the last interglacial period. Paleoceanography, 14, 23-33.

Dahl-Jensen, D., and Coauthors, 1998: Past temperatures directly from the Greenland ice sheet. Science, 282, 268-271.

Dansgaard, W., and Coauthors, 1993: Evidence for general instability of past climate from a $250 \mathrm{kyr}$ ice core. Nature, 364, 218-219.

Davis, B. A. S., and Coauthors, 2003: The temperature of Europe during the Holocene reconstructed from pollen data. Quat. Sci. Rev., 22, 1701-1716.

De Boer, B., R. S. W. van de Wal, R. Bintanja, L. J. Lourens, and E. Tuenter, 2010: Cenozoic global ice-volume and temperature 
simulations with 1-D ice-sheet models forced by benthic $\delta^{18} \mathrm{O}$ records. Ann. Glaciol., 51, 23-33.

deMenocal, P., J. Ortiz, T. Guilderson, and M. Sarnthein, 2000: Coherent high- and low-latitude climate variability during the Holocene warm period. Science, 288, 2198-2202.

Eickhout, B., M. G. J. den Elzen, and G. J. J. Kreileman, 2004: The atmosphere-ocean system of IMAGE 2.2. RIVM Rep. 481508017/2004, 63 pp.

Fasullo, J. T., and K. E. Trenberth, 2008: The annual cycle of the energy budget. Part II: Meridional structures and poleward transports. J. Climate, 21, 2313-2325.

Gersonde, R., X. Crosta, A. Abelmann, and L. Armand, 2005: Seasurface temperature and sea ice distribution of the Southern Ocean at the EPILOG Last Glacial Maximum - A circumAntarctic view based on siliceous microfossil records. Quat. Sci. Rev., 24, 869-896.

Goosse, H., and Coauthors, 2004: A delayed medieval warm period in the Southern Ocean? Geophys. Res. Lett., 31, 1029-1032.

Grootes, P. M., and Coauthors, 1993: Comparison of oxygen isotope records from the GISP2 and GRIP Greenland ice cores. Nature, 366, 552-554.

Hansen, J., and Coauthors, 2007: Climate change and trace gases. Philos. Trans. Roy. Soc. London, 365A, 1925-1954.

- , and Coauthors, 2008: Target atmospheric $\mathrm{CO}_{2}$ : Where should humanity aim? Open Atmos. Sci. J., 2, 217-231.

Herbert, T. D., and J. D. Schuffert, 2000: Alkenone unsaturation estimates of sea-surface temperatures at site 1002 over a full glacial cycle. Proc. ODP, Sci. Results, 165, 239-247.

Houghton, J. T., and Coauthors, Eds., 2001: Climate Change 2001 The Scientific Basis. Cambridge University Press, 881 pp.

Jarvis, A. J., and S. Li, 2011: The contribution of timescales to the temperature response of climate models. Climate Dyn., 36, 523-531.

Jasper, J. P., J. M. Hayes, A. C. Mix, and F. G. Prahl, 1994: Photosynthetic fractionation of $13 \mathrm{C}$ and concentrations of dissolved $\mathrm{CO}_{2}$ in the central equatorial Pacific during the last 255,000 years. Paleoceanography, 9, 781-798.

Jouzel, J., and Coauthors, 2007: Orbital and millennial Antarctic climate variability over the past 800000 years. Science, 317, 793-796.

Kato, S., and Coauthors, 2006: Seasonal and interannual variations of top-of-atmosphere irradiance and cloud cover over polar regions derived from the CERES data net. Geophys. Res. Lett., 33, L19804, doi:10.1029/2006GL026685.

Khodri, M., and Coauthors, 2001: Simulating the amplification of orbital forcing by ocean feedbacks in the last glaciation. $\mathrm{Na}$ ture, 410, 570-574.

Kirst, G., and Coauthors, 1999: Late Quaternary temperature variability in the Benguela Current system derived from alkenones. Quat. Res., 52, 92-103.

Knutti, R., and G. C. Hegerl, 2008: The equilibrium sensitivity of the Earth's temperature to radiation changes. Nat. Geosci., 1, 735-743.

Köhler, P., and Coauthors, 2010: What caused Earth's temperature variations during the last 800000 years? Data-based evidence on radiative forcing and constraints on climate sensitivity. Quat. Sci. Rev., 29, 129-145.

Kuhlemann, J., and Coauthors, 2008: Regional synthesis of Mediterranean atmospheric circulation during the last glacia maximum. Science, 321, 1338-1340.

Laîné, A., M. Kageyama, P. Braconnot, and R. Alkama, 2009: Impact of greenhouse gas concentration changes on surface energetics in IPSL-CM4: Regional warming patterns, land-sea warming ratios, and glacial-interglacial differences. J. Climate, 22, 4621-4635.
Lambert, F., and Coauthors, 2008: Dust-climate couplings over the past 800000 years from the EPICA Dome C ice core. Nature, 452, 616-619.

Larrasoaña, J. C., and Coauthors, 2003: Three million years of monsoon variability over the northern Sahara. Climate Dyn., 21, 689-698.

Laskar, J., and Coauthors, 2004: A long-term numerical solution for the insolation quantities of the earth. Astron. Astrophys., 428, 261-285.

Lawrence, K. T., Z. Liu, and T. D. Herbert, 2006: Evolution of the eastern tropical Pacific through Plio-Pleistocene glaciation. Science, 312, 79-83.

Lea, D. W., D. K. Pak, and H. J. Spero, 2000: Climate impact of late Quaternary equatorial Pacific sea surface temperature variations. Science, 289, 1719-1724.

Lemoine, D. M., 2010: Paleoclimatic warming increased carbon dioxide concentrations. J. Geophys. Res., 115, D22122, doi:10.1029/2010JD014725.

Loulergue, L., and Coauthors, 2008: Orbital and millennial-scale features of atmospheric $\mathrm{CH}_{4}$ over the past 800000 years. Nature, 453, 383-386.

Manabe, S., and A. J. Broccoli, 1985: The influence of continental ice sheets on the climate of an ice age. J. Geophys. Res., 90, 2167-2190.

MARGO project members, 2009: Constraints on the magnitude and patterns of ocean cooling at the Last Glacial Maximum. Nat. Geosci., 2, 127-132.

Martrat, B., and Coauthors, 2009: Abrupt temperature changes in the western Mediterranean over the past 250000 years. Science, 306, 1762-1765.

Mashiotta, T. A., D. W. Lea, and H. J. Spero, 1999: Glacial-interglacial changes in Subantarctic sea surface temperature and $\mathrm{d}^{18} \mathrm{O}$-water using foraminiferal Mg. Earth Planet. Sci. Lett., 170, 417-432.

Masson-Delmotte, V., and Coauthors, 2005: GRIP deuterium excess reveals rapid and orbital-scale changes in Greenland moisture origin. Science, 309, 118-121.

— climate change: Climate model intercomparisons and ice-core constraints. Climate Dyn., 26, 513-529.

- , and Coauthors, 2010a: EPICA Dome C record of glacial and interglacial intensities. Quat. Sci. Rev., 29, 113-128.

- and Coauthors, 2010b: Abrupt change of Antarctic moisture origin at the end of termination II. Proc. Natl. Acad. Sci. USA, 107, 12 091-12 094

Mélières, A., O. Martinerie, D. Raynaud, and L. Lliboutry, 1991: Glacial-interglacial mean sea level pressure change due to sea level, ice sheet and atmospheric mass changes. Global Planet. Change, 3, 333-340.

Miller, G. H., and Coauthors, 2010: Arctic amplification: Can the past constrain the future? Quat. Sci. Rev., 29, 1779-1790.

Mokhov, I. I., and M. G. Akperov, 2006: Tropospheric lapse rate and its relation to surface temperature from reanalysis data. Izv., Atmos. Ocean. Phys., 42, 430-438.

Moreno, A., and Coauthors, 2002: Saharan dust transport and highlatitude glacial climatic variability: The Alboran Sea record. Quat. Res., 58, 318-328.

Nuernberg, D., A. Mueller, and R. R. Schneider, 2000: Paleo-sea surface temperature calculations in the equatorial east Atlantic from $\mathrm{Mg} / \mathrm{Ca}$ ratios in planktic foraminifera. Paleoceanography, 15, 124-134.

Oppo, D. W., and Y. Sun, 2005: Amplitude and timing of sea surface temperature change in the northern South China Sea: Dynamic link to the East Asian monsoon. Geology, 33, 785-788. 
Otto-Bliesner, B. L., and Coauthors, 2009: A comparison of PMIP2 model simulations and the MARGO proxy reconstruction for tropical sea surface temperatures at last glacial maximum. Climate Dyn., 32, 799-815.

Pahnke, K., and J. P. Sachs, 2006: Sea surface temperatures of southern midlatitudes 0-160 kyr B.P. Paleoceanography, 21, PA2003, doi:10.1029/2005PA001191.

—, R. Zahn, H. Elderfield, and M. Schulz, 2003: 340 000-tear centennial-scale marine record of Southern Hemisphere. Science, 301, 948-952.

Pailler, D., and E. Bard, 2002: High frequency Palaeoceanographic changes during the past $140000 \mathrm{yr}$ recorded by the organic matter in sediments of the Iberian Margin. Palaeogeogr. Palaeoclimatol. Palaeoecol., 181, 431-452.

Ramanathan, V., M. S. Lian, and R. D. Cess, 1979: Increased atmospheric $\mathrm{CO}_{2}$ : Zonal and seasonal estimates of the effect on the radiation energy balance and surface temperature. J. Geophys. Res., 84, 4949-4958.

Raval, A., and V. Ramanathan, 1989: Observational determination of the greenhouse effect. Nature, 342, 758-761.

Raymo, M. E., and K. Nisancioglu, 2003: The 41 kyr world: Milankovitch's other unsolved mystery. Paleoceanography, 18, 1011, doi:10.1029/2002PA000791.

Rickaby, R. E. M., and H. Elderfield, 1999: Planktonic foraminiferal $\mathrm{Cd} / \mathrm{Ca}$ : Paleonutrients or paleotemperature? Paleoceanography, 14, 293-303.

Rohling, E. J., 2007: Progress in palaeosalinity: Overview and presentation of a new approach. Paleoceanography, 22, PA3215, doi:10.1029/2007PA001437.

_ P. A. Mayewski, and P. Challenor, 2003: On the timing and mechanism of millennial-scale climate variability during the last glacial cycle. Climate Dyn., 20, 257-267.

_ , and Coauthors, 2008: High rates of sea-level rise during the last interglacial period. Nat. Geosci., 1, 38-42.

- , and Coauthors, 2009: Antarctic temperature and global sea level closely coupled over the past five glacial cycles. Nat. Geosci., 2, 500-504.

— Marine Isotope Stage-11 sea-level histories. Earth Planet. Sci. Lett., 291, 97-105.

Rosenthal, Y., D. W. Oppo, and B. K. Linsley, 2003: The amplitude and phasing of climate change during the last deglaciation in the Sulu Sea, western equatorial Pacific. Geophys. Res. Lett., 30, 1428, doi:10.1029/2002GL016612.

Rostek, F., and Coauthors, 1993: Reconstructing sea surface temperature and salinity using $\mathrm{d}^{18} \mathrm{O}$ and alkenone records. Nature, 364, 319-321.

_ _ E. Bard, L. Beaufort, C. Sonzogni, and G. Ganssen, 1997: Sea surface temperature and productivity records for the past 240 kyr in the Arabian Sea. Deep-Sea Res. II, 44, 1461-1480.

Saraswat, R., R. Nigam, S. Weldeab, A. Mackensen, and P. D. Naidu, 2005: A first look at past sea surface temperatures in the equatorial Indian Ocean from $\mathrm{Mg} / \mathrm{Ca}$ in foraminifera. Geophys. Res. Lett., 32, L24605, doi:10.1029/2005GL024093.

Schaefer, G., and Coauthors, 2005: Planktic foraminiferal and sea surface temperature record during the last $1 \mathrm{Myr}$ across the Subtropical Front, southwest Pacific. Mar. Micropaleontol., 54, 191-212.
Schmidt, M. W., H. Spero, and D. W. Lea, 2004: Links between salinity variation in the Caribbean and North Atlantic thermohaline circulation. Nature, 428, 160-163.

Shine, K. P., and F. Forster, 1999: The effect of human activity on radiative forcing of climate change: A review of recent developments. Global Planet. Change, 20, 205-225.

Siddall, M., and Coauthors, 2003: Sea level fluctuations during the last glacial cycle. Nature, 423, 853-858.

- , and Coauthors, 2004: Understanding the Red Sea response to sea level. Earth Planet. Sci. Lett., 225, 421-434.

—, E. J. Rohling, W. G. Thompson, and C. Waelbroeck, 2008: Marine isotope stage 3 sea level fluctuations: Data synthesis and new outlook. Rev. Geophys., 46, RG4003, doi:10.1029/2007RG000226.

Siegenthaler, U., and Coauthors, 2005: Stable carbon cycle-climate relationship during the Late Pleistocene. Science, 310,1313-1317.

Solomon, S., and Coauthors, Eds., 2007: Climate Change 2007: The Physical Science Basis. Cambridge University Press, 996 pp.

Stanford, J. D., E. J. Rohling, and P. G. Challenor, 2011: Sea level probability for the last deglaciation: A statistical analysis of far-field records. Global Planet. Change, 79, 193-203, doi:10.1016/ j.gloplacha.2010.11.002.

Stenni, B., and Coauthors, 2010: The deuterium excess records of EPICA Dome C and Dronning Maud Land ice cores (East Antarctica). Quat. Sci. Rev., 29, 146-159.

Stewart, R. H., cited 2008: Introduction to physical oceanography [Available online at http://oceanworld.tamu.edu/resources/ ocng_textbook/contents.html.]

Vimeux, F., V. Masson, J. Jouzel, M. Stievenard, and J. R. Petit 1999: Glacial-interglacial changes in ocean surface conditions in the Southern Hemisphere. Nature, 398, 410-413.

Vinther, B. M., and Coauthors, 2009a: Holocene thinning of the Greenland ice sheet. Nature, 461, 385-388.

_ , and Coauthors, 2009b: Climatic signals in multiple highly resolved stable isotope records from Greenland. Quat. Sci. Rev., 29, 522-538.

Waelbroeck, C., and Coauthors, 2002: Sea level and deep water temperature changes derived from benthic foraminifera isotopic records. Quat. Sci. Rev., 21, 295-305.

Wei, G., W. Deng, Y. Liu, and X. Li, 2007: High-resolution sea surface temperature records derived from foraminiferal $\mathrm{Mg}$ / Ca ratios during the last $260 \mathrm{ka}$ in the northern South China Sea. Palaeogeogr. Palaeoclimatol. Palaeoecol., 250, 126-138.

Weinelt, M., and Coauthors, 2003: The role of productivity in the Northeast Atlantic on abrupt climate change over the last 80000 years. Z. Dtsch. Geol. Ges., 154, 47-66.

Weldeab, S., D. W. Lea, R. R. Schneider, and N. Andersen, 2007 155000 years of West African monsoon and ocean thermal evolution. Science, 316, 1303-1307.

Winckler, G., R. F. Anderson, M. Q. Fleisher, D. McGee, and N. Mahowald, 2008: Covariant glacial-interglacial dust fluxes in the equatorial Pacific and Antarctica. Science, 320, 93-96.

Yamamoto, M., M. Yamamuro, and Y. Tanaka, 2007: The California current system during the last 136000 years: Response of the North Pacific high to precessional forcing. Quat. Sci. Rev., 26, 405-414.

Zhao, M., and Coauthors, 1995: Molecular stratigraphy of cores off northwest Africa: Sea surface temperature history over the last 80 ka. Paleoceanography, 10, 661-675. 